\title{
Media Frenzies in Markets for Financial Information
}

\author{
Laura L. Veldkamp * \\ New York University
}

August 27, 2003

\begin{abstract}
Promising emerging equity markets often witness investment herds and frenzies, accompanied by an abundance of media coverage. Complementarity in information acquisition can explain these anomalies. Because information has a high fixed cost of production, its equilibrium price is low when quantity is high. Investors all buy the most popular information because it has the lowest price. Given two identical asset markets, investors herd: asset demand is higher in the market with abundant information because information reduces risk. By lowering risk, information raises the asset's price. Transitions between low-information/low-asset-price and high-information/high-asset-price equilibria raise price volatility and create price paths resembling periodic frenzies. Using equity data and a new panel data set of news counts for 23 emerging markets, the results show that when asset market volatility increases, news coverage intensifies, and that more news is correlated with higher asset prices.
\end{abstract}

${ }^{*}$ NYU Stern School of Business, Economics Department, 44 West 4th Street, 7th floor, New York, NY 10012. email: lveldkam@nyu.edu. Thanks to Xavier Vives, Tim Van Zandt, Thomas Sargent, John Leahy, Boyan Jovanovic, Andrew Rose, Bernard Dumas, Stijn Van Nieuwerburgh, Joe Chen, Pascal Maenhout, Hyun Shin, Paul Pfleiderer, Anat Admati, and seminar participants at NBER summer institute EF\&G meeting, SED meetings, Texas, Wharton, UCSD, Duke Fuqua, Maryland, NYU, Yale, Carnegie Mellon, Pittsburgh, Federal Reserve, Stockholm IIES, Toulouse, Stanford, and INSEAD for helpful comments. Many thanks to Joël Peress for use of software he developed that made the news data collection possible, and to Yuan-Chuan Lien for excellent research assistance. JEL classification: D82, G14, G12. Keywords: Crashes, herding, information market, media. 
The search for the source of frenzies and herds is a search for complementarities in asset demand: How can one person buying an asset make the asset more attractive to other investors? Perhaps the complementarities lie not in the demand for assets, but in the demand for information used to price the asset.

Why look to information markets as the source of frenzies and herds, rather than to asset markets themselves? The reason lies in the non-rival nature of information. Because assets are in fixed supply, an increase in demand must raise the market price, in order for the market to clear. This is not the case for information. An increase in demand for a particular piece of information in a competitive market causes more information to be provided at a lower price. This is the source of the complementarity and the source of large fluctuations in information provision. Investors buy the same information that others are buying because that information is inexpensive. By reducing payoff uncertainty, abundant information raises an asset's price above other equally profitable assets, creating excess price dispersion (herds). Occasionally, there are large shifts in information demand as investors coordinate on a new asset to learn about. Such a shift in information and risk creates large price movements and generates excess price volatility (frenzies).

The innovation in this model comes from an insight of growth theory. Romer (1990) points out that information is fundamentally distinct from other goods because information has a fixed cost of discovery and a near-zero cost of replication. This information production technology, coupled with free entry in the information market, results in information prices that decline as demand rises. This is consistent with observed pricing schemes. Consider the relative prices of one issue of The New York Times, the Economist, Econometrica, and a consultant's report on one firm. The New York Times, the publication of most general interest, is the least expensive. As the audience becomes more specialized, prices rise.

The basis for the model is a Grossman-Stiglitz (1980) economy, where agents decide whether to purchase a signal about an asset's payoff, and then choose their asset demand, given an equilibrium price. In contrast to Grossman and Stiglitz, this model features a competitive information production sector that supplies information at an endogenous price. The setting is similar to Admati and Pfleiderer (1986), who incorporate a monopolistic information supplier. However, competitive 
information provision is crucial to generating information complementarity.

Information affects asset prices and asset markets generate demand for information. Agents who purchase information observe a component of the risky asset payoff. Information reduces the asset's conditional variance. This conditional variance captures uncertainty - an expected distance between beliefs and the true state. In the equilibrium where information is cheap and demand is high, decreased conditional variance raises the asset's price. In the other equilibrium where information is expensive and demand is zero, the asset is riskier and its price is lower. Hence, information moves asset prices. Switches between information equilibria occur because of changes in the asset payoff's unconditional variance. This unconditional variance measures payoff volatility. The model features a state process that ties unconditional variance to expected asset payoffs. When unconditional variance is high, information about the payoff is valuable; a positiveinformation equilibrium arises. With low volatility, a no-information equilibrium prevails. A media frenzy is triggered when an asset payoff increase raises unconditional payoff variance. The added unconditional variance prompts a switch to the positive-information equilibrium. Because it reduces conditional variance, abundant information raises the asset's price above what the improvement in fundamentals would predict.

With multiple markets and an information transmission constraint, the model generates investment herds. Price complementarity makes all investors want to buy information in the same market. With the information constraint, high demand for information in one market crowds out information about another market. Since information raises expected asset prices by reducing conditional variance, two markets with identical parameters and histories can have different asset prices. One market will generate news and the news will raise its asset price; the other will not.

The predictions of the theory are supported by empirical evidence from emerging markets. A new panel data set of Financial Times stories measures information, and data from S\&P measures equity prices. High news levels coincide with high payoff variance and high price levels. The data also confirm the herding prediction that asset price dispersion across markets is high when news is abundant.

Complementarity of information is an idea also present in models of short-term speculation. 
In Froot, Scharfstein and Stein (1992), information serves as an equilibrium coordination device among bubble equilibria. Similarly, Barlevy and Veronesi (2000) structure an asset market to make information acquisition complementary when asset prices are low. Instead, with media frenzies, information markets generate the complementarity.

Media-driven herds result in intense media coverage of booming markets. In contrast, theories of herds (Welch 1992, Banerjee 1992, Bikhchandani et.al.1992, Chari and Kehoe 1999) posit that frenzies arise because too little information is revealed. Data on information provision surrounding asset price booms supports the media frenzy hypothesis. Shiller (2000) documents the increase in press coverage of the stock market as it soared throughout the 1920's. Once-obscure junk bonds became big news in the ${ }^{\prime} 80 \mathrm{~s}$ as returns increased. Investors learned about East Asia and the "miracle" as growth rates climbed to new heights.

\section{A Model of Asset Demand and Information Provision}

\section{Preferences and Technology}

A large finite number of two-period-lived, ex-ante identical agents have constant absolute risk aversion preferences over wealth $\left(W_{t+1}\right)^{1}$

$$
U\left(W_{t+1}\right)=E_{t}\left[-e^{-a W_{t+1}}\right]
$$

There are two assets: one risky asset with payoff $u_{t+1}$, and one riskless asset with payoff $r>1$. The risky asset payoff has a persistent component $\theta$ and an idiosyncratic component $\epsilon$.

$$
u_{t+1}=\theta_{t+1}+\epsilon_{t+1}
$$

The persistent component of payoffs follows an $\operatorname{AR}(1)$ process with mean $\mu$ and proportional shocks $\eta$.

$$
\theta_{t+1}=(1-\rho) \mu+\rho * \theta_{t}\left(1+\eta_{t+1}\right)
$$

\footnotetext{
${ }^{1}$ This utility function is equivalent to a CARA utility function defined over consumption when agents have no bequest motive. They consume all their wealth at the end of life.
} 
Innovations are i.i.d. $\epsilon \sim N\left(0, \sigma_{\epsilon}^{2}\right), \eta \sim N\left(0, \sigma_{\eta}\right)$.

A multiplicative shock to payoffs is a natural assumption in this setting. The proportionality of the mean and standard deviation is a feature of payoff processes shared by exponential processes such as $\theta_{t+1}=\exp \left[(1-\rho) \mu+\rho * \theta_{t}+\eta_{t+1}\right]$. Many papers employ such a process because it delivers scale invariance. Two shares of an asset with expected payoff of $\$ 1$ will have the same payoff variance as one share with expected payoff of $\$ 2$. Furthermore, the assumption that payoff volatility is increasing in its level is supported in the data. ${ }^{2}$ That shocks are multiplicative is important because information demand will depend on the variance of payoffs. This assumption makes the variance of expected payoff innovations $\left(\sigma_{\theta t}\right)$ change over time, and will cause information demand to fluctuate.

\section{Information}

In each period $t$, agent $i$ chooses whether to buy information or not. The information reveals the persistent component of next period's asset payoff $\left(\theta_{t+1}\right)$ at time $t$. The asset payoff $u_{t+1}$ and the state $\theta_{t+1}$ are revealed publicly at the beginning of period $t+1$. For any variable $z$, let $z^{t}$ be the t-history $\left\{z_{0}, \ldots, z_{t}\right\}$. Agents who purchase information at time $t$ have a filtration

$$
\mathcal{F}_{t}^{I}=\left\{\theta^{t+1}, u^{t}, \epsilon^{t}, P^{t}\right\}
$$

and agents who do not purchase information have filtration

$$
\mathcal{F}_{t}^{U}=\left\{\theta^{t}, u^{t}, \epsilon^{t}, P^{t}\right\}
$$

\section{Asset Markets}

The risky asset has price $P_{t}$; the riskless asset price is normalized to one. The per capita supply of the risky asset $x_{t}$ is normally distributed: $x_{t} \sim N\left(E[x], \sigma_{x}^{2}\right)$. This supply is never observed.

\footnotetext{
${ }^{2}$ In the emerging market equity data described in section 6 , a regressing time-t dividend volatility (as measured by squared changes) on the (t-1) dividend level yields a positive coefficient, significant at the $99 \%$ confidence level $(\mathrm{t}$-stat $=4.05)$. Doing the same exercise with payoffs (next-period price plus dividends) yields a positive coefficient with a t-statistic of 16.9 .
} 
However, agents who know $\theta_{t+1}$ can infer the value of $x_{t}$ from the price. The role of the supply shocks is to prevent price from perfectly revealing $\theta_{t+1}$ to uninformed agents.

\section{Information Markets}

The mechanism that generates herds and frenzies is price complementarity in information demand; information prices decline as demand rises. Because information is non-rival, this pricing relationship arises naturally from a number of competitive market structures. This section describes three such markets. To show that results are not dependent on market structure details, all propositions are proven for each market.

The three markets have the following common features. First, information is produced according to a fixed-cost technology. $\theta_{t+1}$ can be discovered at the beginning of period $t$ at a per-capita fixed cost $\chi$. This can be interpreted as the cost of hiring a journalist to interview people and find primary sources of information. The information, once discovered, can be distributed to other traders at zero marginal cost. Second, reselling purchased information is forbidden. The realistic counterpart to this assumption is intellectual property law that prohibits copying a publication and re-distributing it for profit. Third, there is free entry. Any agent can discover information at any time.

That information markets are competitive is crucial. The exact market structure is not. All three markets produce information prices that decrease in demand, complementarity in information acquisition, and frenzies. The most tractable market is price competition. This is the market structure that is used for numerical analysis in section 4. However, the perfectly competitive outcome in this market is fragile. A small sunk cost would deter new entry. Free from threats of competition, the producer could price as a monopolist (Vives 1999). Because a monopolist's price does not decrease in demand, complementarity in information would disappear. The Cournot model yields a price that can only be expressed as an implicit function, but has a less fragile equilibrium. The monopolistic competition model with its variety of information types is the most common setting used to analyze information supply (e.g. Shapiro and Varian 1998). 
Market I: Price Competition in a Perfectly Contestable Market Profits from information discovery depend on the price charged and demand for information, given the pricing strategies of other agents. The market is perfectly contestable. ${ }^{3}$ Let $d_{i t}=1$ if agent $i$ decides to discover information in period $t$ and $d_{i t}=0$ otherwise. Let per capita demand for information with price $c_{i t}$, given all other posted prices $c_{-i t}$, be $I(\cdot, \cdot)$. Then the objective of the information producer is to maximize profit.

$$
\max _{d_{i t}, c_{i t}} d_{i t}\left(c_{i t} I\left(c_{i t}, c_{-i t}\right)-\chi\right)
$$

Market II: Cournot Competition Profits from producing information depend on the quantity of information production chosen, as well as the quantities chosen by all other producers. Let the price for information when agent $i$ produces $\tilde{d}_{i t}$ copies of news, per capita, and all other agents produce a per capita quantity $\tilde{d}_{-i t}$, be $\tilde{c}(\cdot, \cdot)$. The objective of the information producer is to maximize profit.

$$
\max _{\tilde{d}_{i t}} \tilde{d}_{i t} \tilde{c}\left(\tilde{d}_{i t}, \tilde{d}_{-i t}\right)-\chi \mathbf{1}_{\tilde{d}_{i t}>0}
$$

Market III: Monopolistic Competition with Versions of Information Agent $i$ has preferences over wealth and the type of news she receives, $j$.

$$
U\left(W_{t+1}, j\right)=-e^{-a\left(W_{t+1}-\psi_{i j}\right)}
$$

Each news type has the same fixed cost of production $\chi$, and contains the same information $\theta_{t+1}$. All types convey the same facts about an event. However buyers may have different costs of acquisition, or different opportunity costs for the time spent processing the information, depending on the medium or reporting style. ${ }^{4}$ If the consumer does not buy news, then $j=0$ and $\psi_{i j}=0$. Each consumer buys at most one type of news and only one unit of that type. There is a large,

\footnotetext{
${ }^{3}$ One way to ensure that the market is contestable is to force agents to choose prices in a first stage and choose entry in a second stage. This is a reasonable way to think of news markets where the price of the periodical is fixed well in advance and then editors decide whether or not to supply a story. By supplying the story, they would be entering the market for that piece of information.

${ }^{4}$ Preferences over news types take the form of individual-specific costs. This assumption allows a convenient nesting of price-setting and Cournot models inside this setup. The qualitative results are the same for additive preferences over news types.
} 
finite number $K$ of news types. Consumer i's preferences over type $j$ are independent across types and consumers and are distributed uniformly: $\psi_{i j} \sim \operatorname{unif}[0, b]$.

The information demand function is the same as the pure price-competition model except that demand is a function of the producer's information type $j$, as well as the set of all types produced $J$. Agents decide whether to produce information $d_{i t} \epsilon\{0,1\}$, choose a type $j$ and charge a price $c_{i t}$ to maximize their expected profit.

$$
\max _{d_{i t}, j, c_{i t}} d_{i t}\left(c_{i t} I\left(c_{i t}, j, c_{-i t}, J\right)-\chi\right)
$$

\section{Order of Events}

1. All agents enter the first period of life knowing the persistent component of the period $t$ asset payoff $\theta_{t}$ and $\sigma_{\theta t}$, the variance of $\theta_{t+1}$, conditional on $\theta_{t}$.

- Agents decide whether to discover information, what type to discover, and what price or quantity to set.

- Agents choose whether or not to purchase information. Informed agents observe $\theta_{t+1}$.

- Informed and uninformed agents demand $D^{I}$ and $D^{U}$ units of the risky asset.

2. Payoffs are received. The asset supply $x_{t}$ and the asset payoff $u_{t+1}$, with its persistent and transitory components $\theta_{t+1}$, and $\epsilon_{t+1}$ are revealed.

3. In the second period of life, agents derive utility from terminal wealth $W_{t+1}$.

\section{Equilibrium}

Given an initial wealth, a persistent asset payoff process, payoff shocks, and risky asset supply, $\left\{\theta_{t}, \epsilon_{t}, x_{t}\right\}_{t=1}^{\infty}$, an equilibrium is a sequence of risky asset demands and a fraction of investors who purchase information $\left\{D_{i t}, \lambda_{t}\right\}_{t=1}^{\infty}$, and asset prices, information prices $\left\{P_{t}, c_{t}\right\}_{t=1}^{\infty}$, such that in every period $t>0$

1. Given prices $\left\{P_{t}, c_{t}\right\}$, agents choose whether to buy information of type $j\left(I_{i j t}=1\right)$, or not $\left(I_{i j t}=0\right)$, and choose asset demands to maximize expected utility (1), or (4) for monopolistic 
competition, subject to their budget constraint, ${ }^{5}$

$$
W_{t+1}=\left(W_{t}-P_{t} D_{i t}-I_{i t} c_{j t}\right) r+D_{i t} u_{t+1}+\pi_{i t}
$$

$\lambda_{t}$ is the fraction of agents who buy information.

2. Information supply and pricing strategies are a subgame perfect Nash equilibrium. They solve (2), (3), or (5), depending on the information market structure.

3. The markets for risky assets and information clear.

\section{Complementarity, Equilibrium Transitions and Asset Prices}

This section derives properties of equilibrium information provision and describes the interaction between information and asset prices. All three information markets produce information prices that decline as demand rises (proposition 1). This price complementarity makes investors want to coordinate their information purchases (proposition 2). The equilibrium prescribes either no information or a large amount of information provision. What moves the economy between high and low information equilibria is fluctuations in asset payoff volatility $\sigma_{\theta t}$ (propositions 3 and 4 ). The model ties volatility to the expected payoff of the asset $\theta_{t}$, and in turn, to the asset price. When the expected payoff is high, the price, the volatility, and the information demand are high as well. The economy is in a positive information equilibrium. Because information decreases the conditional variance of the asset payoff, it increases the price (proposition 5). When expected payoff and price are low, the economy is in the no-information equilibrium. In these periods, the price in this model is identical to the price in a model with no information markets. Thus, information increases unconditional price variance by further increasing prices during times when prices are already at their highest levels.

\section{Proposition 1 Information Price Declines in Quantity}

\footnotetext{
${ }^{5}$ Because of constant absolute risk aversion preferences, end-of-period information revelation, and the Markov state process, maximizing next period utility would also be optimal for an infinitely-lived agent.
} 
All three market structures produce an equilibrium price for information $c(\lambda)$, that is a decreasing function of the quantity of information purchased, $\lambda$.

All proofs are in the appendix. This result follows from the free entry assumption. As information demand rises, producers must produce more and reduce prices to deter new entrants. The result is more surplus for information purchasers. The price competition and competitive monopolist models yield average cost pricing. Because of the fixed cost in information production, average cost declines as the number of information purchasers rises. In the Cournot market, when information demand rises, the producer must raise quantity to deter new market entrants. This results in a lower price.

A price that falls as demand rises produces price complementarity. An information purchase by one agent has two opposing effects on other agents' information demand. An increase in information demand makes information cheaper and therefore more desirable to uninformed agents. However, increased information provision makes the asset price more informative, decreasing the value of information. Let the net benefit to the purchaser of the $\lambda N$ th signal be denoted by $B\left(\lambda ; \theta_{t}\right)$. Grossman and Stiglitz show that the expected net benefit of information is

$$
B(\lambda)=\left[\frac{\operatorname{var}\left(u_{t+1} \mid P_{t}\right)}{\operatorname{var}\left(u_{t+1} \mid \theta_{t+1}\right)}\right]^{1 / 2}-e^{a\left(c\left(\lambda_{t}\right)+\tilde{\psi}\right)}
$$

where $\tilde{\psi}$ is the lowest cost news type for the marginal buyer of news. ${ }^{6}$ The first term is the benefit of information (plus one). When the variance of payoffs given the price $\left(\operatorname{var}\left[u_{t+1} \mid P_{t}\right]\right)$ is greater than the payoff variance given information $\left(\operatorname{var}\left[u_{t+1} \mid \theta_{t+1}\right]\right)$, then information provides some benefit. The second term is the utility cost of information (plus one). The difference between the information purchasing decision in this model and in Grossman and Stiglitz is the endogenous price of information $c\left(\lambda_{t}\right)$, rather than a constant information price $c$.

\section{Proposition 2 Information Complementarity}

At every $\theta_{t}$, the expected net benefit of purchasing information $B\left(\lambda ; \theta_{t}\right)$ is increasing in the fraction of agents that are informed $\lambda$, over some range $\lambda \epsilon\left[0, \lambda_{t}^{\star}\right)$.

\footnotetext{
${ }^{6}$ In the price competition or Cournot models, $\tilde{\psi}=0$.
} 
The fall in the net benefit of information as the number of informed agents rises is the effect identified by Grossman and Stiglitz (1980). When more agents act knowing $\theta_{t+1}$, the price level is more informative. When the price reveals more information, purchasing that information becomes less attractive. In Grossman and Stiglitz, the net benefit curve is monotonically decreasing and there can be only one equilibrium. When the information price in endogenous, the net benefit curve has an increasing part. Price complementarity is the force that makes the net benefit of information rise in the number of informed investors. The non-monotonic net benefit function is responsible for the discrete changes in information regimes.

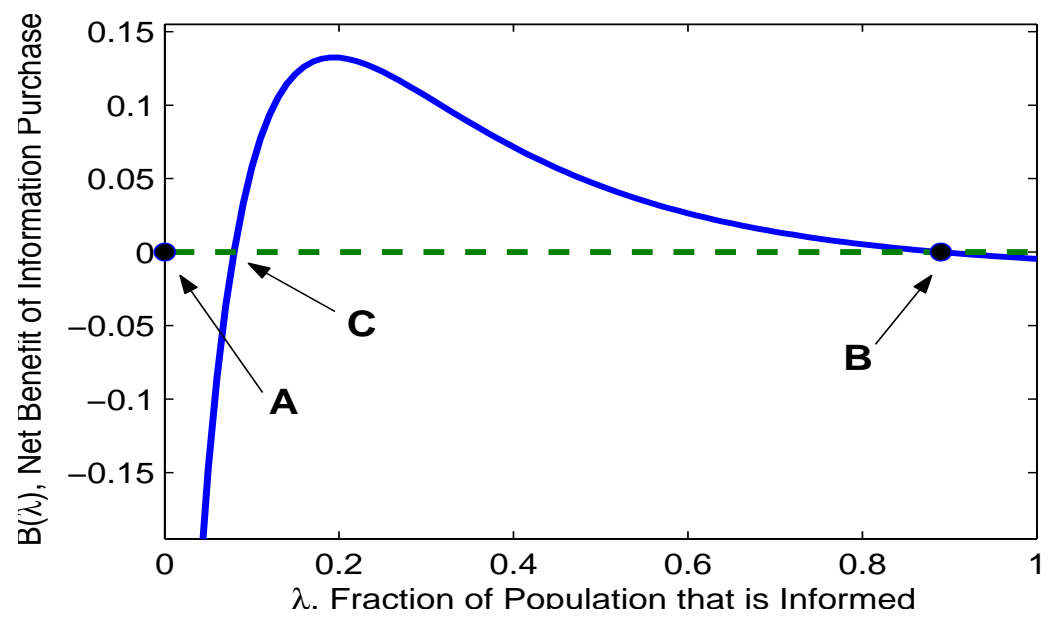

Figure 1: Expected net benefit of information, as the aggregate demand for information varies.

\section{Equilibrium Transitions}

In equilibrium, information demand $\lambda^{e}$ is such that all purchasers of information weakly prefer to have information, and no additional agents want to purchase $B\left(\lambda^{e} ; \theta_{t}\right)=0$-points $\mathbf{A}, \mathbf{B}$ and $\mathbf{C}$ in figure $1 .^{7}$ If no one purchases information, the first person to buy must incur the entire fixed cost of information production. A high information fixed cost ensures that no information is an equilibrium. With a large number of agents, even a near-zero per-capita fixed cost causes the cost of buying the first signal to outweigh its benefit. When many people purchase information, the cost of discovery is shared, information is cheap and signals are a more attractive purchase.

\footnotetext{
${ }^{7}$ The parameter values used to generate the graph are: $\sigma_{\theta}=0.1, \sigma_{\epsilon}=0.1, \sigma_{x}^{2}=10, a=0.7, \chi=1.8, n=50$.
} 
Although A, B and $\mathbf{C}$ could all be equilibria for information demand, only $\mathbf{B}$ is also an equilibrium in information supply. The reason is that the market in figure 1 can support a large information supply. An agent in a state where no other agents are producing information $(\mathbf{A})$ or where production is very limited $(\mathbf{C})$ can make a profit by discovering information and either selling it at a lower price, or increasing the quantity supplied.

\section{Proposition 3 Information Equilibrium Transition Rule}

For a given set of positive, finite-valued parameters, $\sigma_{\eta}, \sigma_{\epsilon}, \sigma_{x}, a, \chi,\left\{\psi_{i}\right\}$, there exists a cutoff $\theta^{\star}$, such that for all $\theta_{t} \geq \theta^{\star}, \lambda_{t}^{e}>0$ and for all $\theta_{t} \leq \theta^{\star}, \lambda_{t}^{e}=0$, in equilibrium.

What causes the net benefit of information for a given demand $\lambda$ to fluctuate, is changes in the volatility of the asset payoff. When volatility is high, information that reveals the level of $\theta_{t+1}$ is more valuable. Recall that the variance $\operatorname{var}_{t}\left[\theta_{t+1}\right]=\rho^{2} \theta_{t}^{2} \sigma_{\eta}^{2}$ is increasing in the level of asset payoff $\theta_{t}{ }^{8}$ Therefore, increases in $\theta_{t}$ shift the net benefit curve up. When $\theta_{t}$ is very low, the entire net benefit curve may lie below zero. These are times when no positive information equilibrium exists. The cutoff payoff level $\theta^{\star}$ makes the peak of the net benefit curve lie at zero.

The reason that the expected level of payoffs should increase information demand is that a piece of information that tells you if you will gain or lose $50 \%$ on an investment that is worth $\$ 10$ is not as valuable as information on whether you will gain or lose $50 \%$ on an investment worth $\$ 100$. All else equal, we want to know more about higher-value markets because they have more value at risk.

\section{Information and Asset Prices}

This section derives two predictions of the model that relate information to asset prices. These predictions are tested with asset price and news data in section 6 . The first prediction is that an increase in asset payoff volatility causes an increase in information provision. The second is that the expected asset price increases with more information provision.

\section{Proposition 4 Payoff Volatility Increases Information}

\footnotetext{
${ }^{8}$ Large, negative asset payoffs could also generate information demand in equilibrium. However, this is a rare occurrence because the mean of $\theta$ is above zero.
} 
The fraction of informed investors $\lambda_{t}$ is a non-decreasing function of the variance of persistent payoff innovations $\sigma_{\theta t}^{2}$.

The dependence of information on payoff variance has two components: risk and information's increasing returns. Risk, measured as the expected squared percentage change in payoffs, increases information demand because information that predicts payoffs is most valuable when large payoff changes are likely. The mean of payoffs matters because the benefit of information increases in the value of the asset. Assets with a higher expected payoff comprise a larger share of the average investor's portfolio. Information about an $\mathrm{x} \%$ change in an asset that is $50 \%$ of a portfolio is more valuable than the same information about an asset worth $5 \%$ of the portfolio. The total variance is the risk of the asset, interacted with the value of the asset at risk.

\section{Proposition 5 Information Increases Asset Price}

The expected price of the risky asset $E\left[P_{t} \mid \theta_{t}, \lambda_{t}\right]$ is strictly increasing in the amount of information provision $\lambda_{t}$.

Changes in information equilibria move the asset price by changing the variance of the asset's payoffs. Grossman and Stiglitz show that an expected utility maximizing agent $i$ with information $\mathcal{F}_{t}^{i}$ who observes equilibrium asset price $P_{t}$, demands $D\left(\mathcal{F}_{t}^{i}, P_{t}\right)$ units of the risky asset.

$$
D\left(\mathcal{F}_{t}^{i}, P_{t}\right)=\frac{E\left[u_{t+1} \mid \mathcal{F}_{t}^{i}, P_{t}\right]-r P_{t}}{a \operatorname{Var}\left[u_{t+1} \mid \mathcal{F}_{t}^{i}, P_{t}\right]}
$$

The unique market clearing price $P_{\lambda}\left(\theta_{t+1}, x_{t}\right)$ for a given information demand $\lambda_{t}$ equates total demand for the risky asset with supply.

$$
\lambda_{t} D\left(\mathcal{F}^{I}, P_{t}\right)+\left(1-\lambda_{t}\right) D\left(\mathcal{F}^{U}, P_{t}\right)=x_{t}
$$

When more information is provided to the market, the conditional risk of the asset payoff, $\operatorname{Var}\left[u_{t+1} \mid \mathcal{F}_{t}^{i}, P_{t}\right]$, is lower. Lower risk makes the asset more attractive to investors, increases demand and raises the price. Information raises the conditional expectation of the price. However, realized 
prices can be lower with information, if the information predicts low asset payoffs (if $E\left[u_{t+1} \mid \mathcal{F}_{t}^{i}, P_{t}\right]$ is low).

Two features of positive information equilibria produce large asset price volatility. First, switches between positive-information and no-information equilibria create abrupt changes in information demand. These sudden changes in information levels cause large jumps in the price level: Large decreases in payoff uncertainty increase the price. Second, positive information equilibria exist when $\theta_{t}$ is high. A high $\theta_{t}$ means a high expected asset payoff, and a high asset price. Hence, positive information equilibria exist and raise prices when prices are already high. By making the most extreme price realizations more extreme, small information effects can have large consequences for the variance of prices. The extent of this excess price volatility is assessed in the numerical example.

\section{Bringing the Model to Data}

\section{Data}

To assess the magnitude of the model's frenzies and test the model's predictions requires data on equity markets and financial news. The data is a panel consisting of weekly observations of a price index, total return index and the number of news stories pertaining to 23 emerging markets between 1989 and 2002. (12,217 observations) Table 8 contains descriptive statistics for the news and price data.

The price and return indices are from the S\&P/IFCI Emerging Markets Database. The price index measures a country's market capitalization and the total return index measures market capitalization plus cash dividends. Since the model's assets are two-period-lived, the total return index (price plus dividends) of an infinitely-lived asset is the equivalent of the payoff of the model assets. Weekly observations are the Friday level of the index. All countries get an index of 100 at the time they enter the sample. Therefore, only index comparisons within a country are meaningful. For calibration, I use percentage deviations of price from country mean. Since the dividends extracted from these series are highly cyclical, dividend data are 6-month backwards-looking moving averages. 
I collect news stories from the Financial Times that contain the name of the country or the adjective form of that name, in the title or lead paragraph. The reason for using only the Financial Times is that a single news source avoids double-counting, its number of emerging market stories is not trending, and examination of a random sample showed this source to have largest fraction of relevant stories. Out of a random sample of 100 Financial Times stories that satisfied the selection criteria, 97 contained some information related to the strength of the emerging market or the value of its assets. The reason for using emerging market rather than firm-level data is that selecting stories related to a country's economy is easier than selecting stories for a given firm. Which stories at the industry and country level are relevant to that firm is less clear-cut.

\section{Linking $\lambda$ to News Stories}

The monopolistic competition model of the information market can be used to bridge the gap between the fraction of informed agents $\lambda$ in the theory and the number of news stories (or simply stories) in the data. When the demand for information about a market rises, more stories are printed. This number of stories can be interpreted as varieties of the same information. Using the monopolistic competition framework, the number of stories is formally tied to $\lambda$. Stories can also be interpreted as conveying different information, in an extension of the model.

Varieties of the Same Information Assume that stories have the same properties as the news types in the monopolistic competition model. Each story conveys the same information $\theta_{t+1}$. Besides conveying information, each story provides some direct utility cost or benefit. Each story is a different type $j$ and has a different utility cost for agent $i, \psi_{i j} \sim \operatorname{unif}[\underline{b}, \bar{b}]$. Let $b=\bar{b}-\underline{b}$. Each story has the same fixed cost of production $\chi$. Producers of stories compete by choosing information price $c_{j}$ to maximize their profit.

Under these assumptions, appendix A.1 shows that the equilibrium number of stories will be proportional to $\lambda^{1 / 2}$.

$$
q=\left(\frac{b \lambda_{t}}{a \chi} e^{a W_{I}}\right)^{1 / 2}
$$


Varieties of Different Information Another way to relate the number of Financial Times stories to the model is to interpret each story as a noisy signal about the true future state $\theta_{t+1}$. In this setting, each agent might want multiple stories to increase the accuracy of their information. This extended model is set up in Appendix B. The intuition for the mechanism is outlined here.

Suppose that each time a supplier incurs the cost of discovery, he draws a different noisy signal of the state, a different story. Identical copies of each story can be made at zero marginal cost and sold to other agents. Another new assumption is that the cost of information discovery falls in the number of information types. If $q$ stories are discovered, the cost of discovery is $\tilde{\chi}(q), \tilde{\chi}^{\prime}(q)<0$ and $\tilde{\chi}^{\prime \prime}(q)>0$. The declining cost captures the idea that an organization producing lots of news about a country has an infrastructure set up to collect this information, and will have an easier time marginally increasing its information production.

News stories exhibit the same price complementarities and decreasing marginal value of information as does $\lambda$, the fraction of informed investors. It is these competing forces that generate the frenzies in the model. News stories are complements because the equilibrium price of a news story falls when many are supplied. News stories are substitutes because they are correlated signals. In expectation, each observed news story provides less additional information than the previous story. When news is scarce, the decrease in the price of news is the dominant force; the net benefit of the next news story is increasing. When news is abundant, information content declines; the net benefit of additional stories falls. Because demand functions for $\lambda$ and news stories have the same form, a news stories measure behaves similarly to the fraction of informed investors $\lambda$ in the original model. A single demand for information $\lambda$ does not exist in this model. Rather, there are identical demands $\lambda_{q}$ for each story in positive supply. As $\lambda_{q}$ rises, so will the equilibrium number of stories.

\section{A Numerical Example}

The goal of the model simulation is to examine the qualitative features of the price time-series and to demonstrate that the model is capable of generating excess volatility comparable to that in the data. 


\section{Calibration}

The information market I will calibrate is model I: price competition in a perfectly contestable market. The per-capita cost of information discovery $\chi$ is such that no-information and positiveinformation equilibria exist. The mean and variance of risky asset supply $E[x]$ and $\sigma_{x}$, determine the price level and the amount of idiosyncratic noise in the price. They are chosen to be large enough to create non-trivial uncertainty about fundamentals, but not to drown out other sources of price fluctuation. Autocorrelation $(\rho)$ of $\theta$ is equal to the weekly autocorrelation in the price indices. Variance of payoff shocks $\sigma_{\epsilon}$ determines the risk of investment for informed traders and the scale of the asset price. It is as large as the asset supply shocks. Absolute risk-aversion $a$ is 2.5. Finally, the variance of innovations to fundamentals $\sigma_{\eta}$ is chosen to match the price level variance in the data with the model. ${ }^{9}$

\section{Results: Frenzies}

Because information reduces the conditional risk of the asset payoff, it increases the asset's price. Therefore, changes in the amount of information sold to investors increases price volatility. Two features of the model amplify this effect. First, information is demanded only when asset payoffs and prices are high. Provision of information pushes already high prices up higher. Movements in extreme price levels have large consequences for the unconditional price variance. Second, changes in information provision are large. A switch from a no-information equilibrium to a positive information equilibrium can increase the fraction of informed agents by $80 \%$ in a single period.

\begin{tabular}{||c|c|c|c||}
\hline & No-Information Model & Information Model & Emerging Market Data \\
\hline Price Standard Deviation & 0.29 & 0.39 & 0.43 \\
\hline$\frac{\operatorname{Var}(\text { Price })}{\operatorname{Var}(\text { Price|Low News })}$ & 1.0 & 1.8 & 1.3 \\
\hline
\end{tabular}

Table 1: Standard deviations of simulated variables and log price indices for 23 emerging markets. Low news is defined as a level of $\lambda$, or count of news stories that falls below its median. Moments computed on a country-bycountry basis and then averaged. Simulated price changes are log changes. 5000 simulations.

One measure of the magnitude of frenzies is the ratio of price variance from simulations of the model with and without information markets: $\frac{\operatorname{var}\left(P_{\text {info }}\right)}{\operatorname{var}\left(P_{n o} \text { info }\right)}=1.5$. Information markets increase

\footnotetext{
${ }^{9}$ The parameter values are: $\chi=0.012, E[x]=6, \sigma_{x}^{2}=1.6, \sigma_{\eta}=0.09, \sigma_{\epsilon}=0.1, \rho=0.99, a=2.5$. The average relative risk aversion is 6 .
} 
the price volatility by $50 \%$. This is consistent with Mankiw, Romer and Shapiro's (1991) finding that equity prices from 1872-1987 exhibit excess volatility of about 50\%. Since the no-informationmarket price is not observed in the data, a frenzies measure based on observables is needed to compare the model with the data. Using the price in periods when news provision is low can proxy for the no-information price in the model. In periods when $\lambda=0$, the prices in the models with and without information markets are the same. Table 1 displays the unconditional price variance divided by the variance of price conditional on observing an information level below its median. The low news price variance in the model is price variance in the $50 \%$ of periods when $\lambda$ is lowest ( $\lambda$ is always zero in these periods). In the data, the low news prices are observations where the number of news stories is less than the median of all news observations. An alternative procedure using the country median to distinguish low-news and high-news times produces a variance ratio of 1.2. The comparison only suggests that the model's effect can be large enough to be a potential explanation for frenzies.

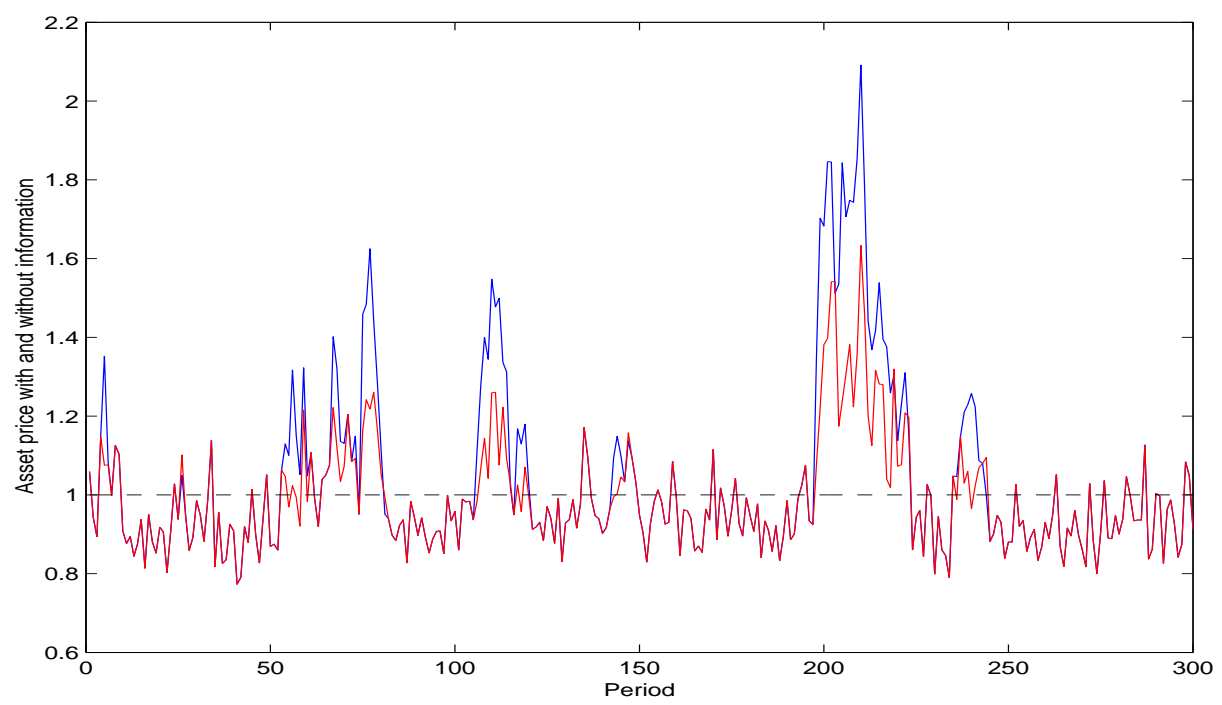

Figure 2: Simulated asset prices in the no-information model (lower line) and information model (upper line). Excess price volatility: $\frac{\operatorname{var}\left(P_{\text {info }}\right)}{\operatorname{var}\left(P_{\text {no info }}\right)}=1.5$

Figure 2 plots the price series generated by the model and a version of the model where no information is ever provided. When the information model is in a no-information equilibrium, the asset price is the same as if information markets didn't exist; the two prices lie on top of each other. 
It is only when there is positive demand for information that the model's prices deviate from the no-information benchmark.

The model's prices display recurrent over-reactions to changes in fundamentals. For example, a $20 \%$ deviation of the no-information price from trend can cause a $60 \%$ movement in the price with information. (See periods 75-80 in figure 2.) The reason is that the model breaks the link between fundamentals and prices, precisely when the changes in fundamentals are large. These large changes are most likely to move information demand. It is the shift in information demand that amplifies the price change. The conditional correlation of price and fundamentals reveals this effect. Figure ?? plots the probability of price and fundamental changes being in the same percentile bin, conditional on the change in fundamentals. Small and medium-size price changes are tightly linked to changes in fundamentals. Large price increases or decreases are not.

An issue that arises in examining the asset price series is the validity of comparing this sequence of two-period asset prices to the price of multi-period assets in the data. The difference between the assets' payoffs is price risk. While the two-period asset payoff is exogenous, the multi-period asset payoff depends on the future expected asset price. This payoff differential is especially large near $\theta^{\star}$, where an information regime shift and thus a large change in prices is likely. Replacing the two-period asset with a multi-period asset should cause the price path around the cutoff point where the information regime shift occurs to be smoother. Agents in a no-information state who anticipate a likely media frenzy tomorrow will value the asset more highly because large capital gains are likely. Agents in the high-information state who anticipate the imminent end of the media frenzy will reduce their value of the asset to hedge the risk of a price fall. However, when the asset payoff is either a high or low outlier, the chance of a regime shift is small and price risk is low. In these states, the two-period and multi-period assets will produce similar prices.

To isolate the quantitative contribution of information price complementarity, we can compare a model with a fixed information price to the media frenzies model. The fixed information price model is similar to Grossman-Stiglitz, but uses the dynamic state process from this model to make information abundant when asset prices are high. The only difference between these two models is that the Grossman-Stiglitz version holds the price of information equal to the average price of 
information in the media frenzies model; the media frenzies information price varies endogenously. Simulations (10,000 iterations) show that an endogenously varying information price causes the asset price volatility to be $40 \%$ higher than in a fixed-information-price setting.

\section{$5 \quad$ Herding in a Model with Multiple Markets}

In a setting with multiple investment markets, complementarity in information acquisition causes media herds. An abundance of media attention is focused on one, or a subset of markets. Information on the herd market is cheap. No information is available on the other markets because any investor who wanted to purchase a signal would have to pay the entire fixed cost. The markets with information have a higher asset price because the conditional variance of their payoff is lower. When expected payoffs in a high information market start to fall, other markets may become more attractive media markets because their risk and payoff are higher. There will be a quick switch in equilibria as demand for information shifts from one market to the other. The shift in information provision causes a fall in one asset price and a rise in the other. The result is that identical markets have different equilibrium prices, and that prices exhibit excess cross-sectional volatility, relative to fundamentals.

The new assumption introduced in this section is a trade-off between purchasing information about one market or another. This assumption is crucial because without any interaction between information demands, each market would have an independent price process, as described by the one-market model. The trade-off is enforced through a constraint on the number of signals each agent can purchase. This assumption can be interpreted as a constraint on space in newspapers, on information processing abilities (as in Sims 2001), or a budget constraint.

Preferences, technology and information structure are identical to those in section 1, except for the following two modifications. First, there are $M$ markets, indexed by $m$. Each market has an independent payoff process.

$$
\begin{gathered}
u_{t+1}^{m}=\theta_{t+1}^{m}+\epsilon_{t+1}^{m} \\
\theta_{t+1}^{m}=(1-\rho) \mu+\rho * \theta_{t}^{m}\left(1+\eta_{t+1}^{m}\right)
\end{gathered}
$$


Innovations are i.i.d. normal, across time and markets. For simplicity, assume the shocks have common variances $\sigma_{\eta}^{2}, \sigma_{\epsilon}^{2}$. As before, define $\sigma_{\theta t}^{m}=\rho \theta_{t}^{m} \sigma_{\eta}$. Second, there is an information transmission constraint. Each agent can observe, at most, $k$ signals.

One way to isolate the herding effect of the model is to examine markets that are ex-ante identical and show that their price levels diverge. The following proposition shows that, when there is enough information demand, information constraints force some markets to a zero-information equilibrium and create a wedge between the asset prices in markets with media coverage and markets without.

\section{Proposition 6 : Herding}

Suppose that $\tilde{m}$ markets have identical histories $\left(\theta^{t+1}, \epsilon^{t}, x^{t}\right)$ and identical parameters and that agents can purchase at most $k$ signals. Let $\lambda^{\star}=\operatorname{argmax}_{\lambda} B(\lambda)$. If $\lambda^{\star}>k / \tilde{m}$, then the price of the risky asset is not identical across markets. The asset price is higher in the markets with higher information provision $\lambda_{m t}$.

When most markets are performing poorly, and total information demand is low, the information transmission constraint does not bind. In these periods, the equilibrium is identical to the onemarket equilibrium, where the net benefit of an additional signal purchased is zero: $B^{m}\left(\lambda^{m}\right)=0$.

When risk and asset payoffs are high in many markets, the information transmission constraint binds. Equilibrium information demand equates the net benefit of information purchased across all markets that supply information. Agents purchase information only in markets that can offer the equilibrium net benefit level $b_{t}$. Information trade-offs occur when the net benefit of signals in one market shifts up (either due to a reduction in the information cost or a rise in $\theta$ ). This makes the information purchasing constraint bind more tightly and increases the cutoff level $b_{t}$. To maintain the higher net benefit, the information quantities in other markets must fall. A market that is near the peak of its net benefit curve $\lambda^{\star}$ may be driven to a no-information equilibrium when another market performs well, because no positive amount of information could result in a net benefit that exceeded the cutoff level $b_{t}$. Figure 3 illustrates this information crowd-out effect.

Because abundant information raises the price of an asset, information trade-offs result in asset- 


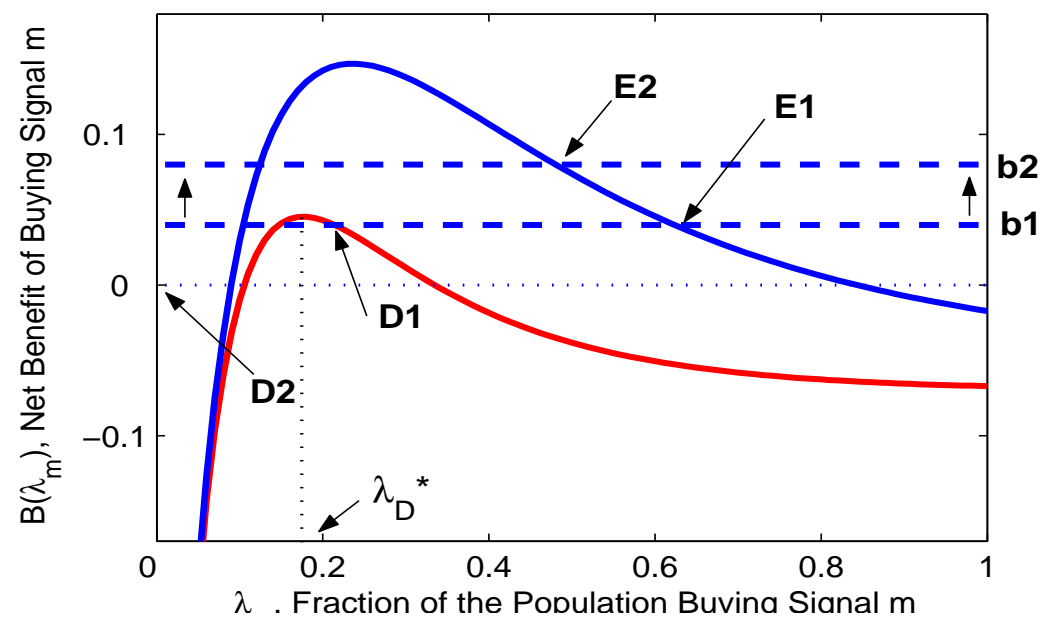

Figure 3: Information crowd-out. Higher demand for information in a third market (not in graph) raises the net benefit cutoff level from b1 to b2. Information demand in market $E$ falls from $E 1$ to $E 2$. Information demand in market $D$ falls to zero.

price trade-offs and higher cross-sectional price variance. An asset whose expected payoff $\theta_{t}$ and volatility $\sigma_{\theta t}$ are higher than other assets generates abundant media coverage. The information raises the highest price further above the other prices. A pattern of media attention successively raising one asset price above the rest can be seen in figure 4 . In the calibrated model, the ratio of the average cross-section price variance with information to variance without information is 1.5.

\section{Evidence of Media Frenzies and Herds}

Three relationships between news and asset prices are predicted by the model: Asset payoff volatility feeds the demand for news; news increases asset price, and news increases price dispersion across markets. (propositions 4, 5 and 6) All three are supported by the data. The positive relationship between asset market volatility and news is predicted by both this model and Grossman-Stiglitz. However, this model adds that volatility should be high when asset payoffs are also high. The data supports the hypothesis that high volatility and high payoffs both cause information provision to increase. Furthermore, the data provides strong evidence of a positive correlation between news and asset price levels. The final and most surprising result is that the data displays positive covariance of news and price dispersion. News increasing price dispersion is a distinguishing feature of this model. This result supports the link between information complementarities and asset markets. 

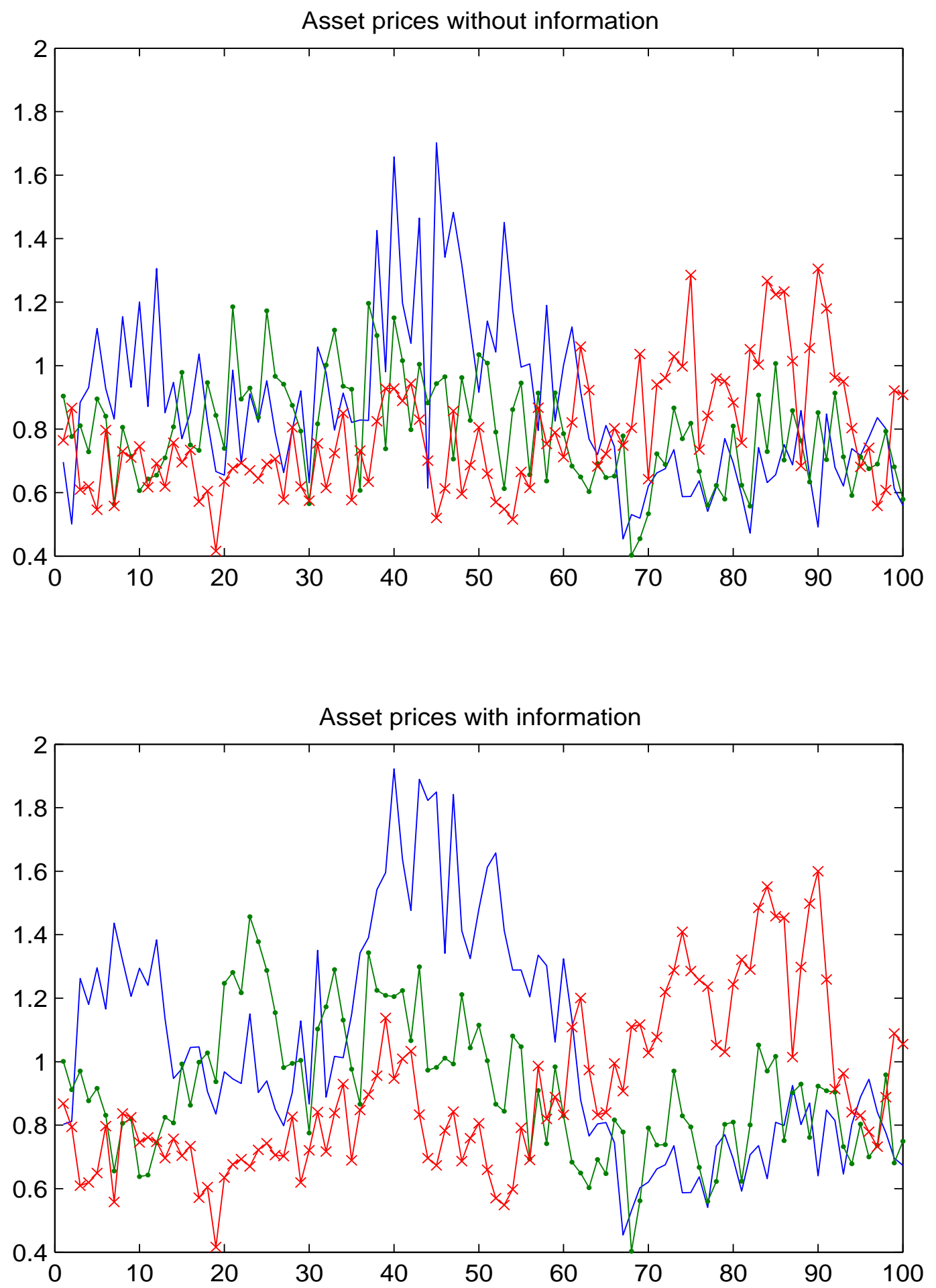

Figure 4: Price of the risky asset in three markets where information trade-offs are present. The two panels show the price level with and without information markets. The information market drives a wedge between the markets covered in the media and the non-covered markets. The result is increased cross-sectional price dispersion. The cross-sectional variance in price is 1.5 times higher in the market with information. This simulation uses the same parameter values as the simulation in section 4 . The number of signals an agent can purchase each period is one and the total number of markets is three. 


\section{Asset Price Volatility and News}

Previous work in empirical finance (Roll 1988, Mitchell and Mulherin 1994) has viewed news as an exogenous process that moves price. One of the contributions of this work, both empirical and theoretical, is to show that news should be thought of as an endogenous variable that interacts with asset markets. Proposition 4 shows that markets with higher asset payoff volatility $\sigma_{\theta t}$ should generate more news, holding their parameters constant. ${ }^{10}$ The reason is that higher payoff volatility represents higher risk. More risk makes information more valuable and increases demand.

\begin{tabular}{||c|c|c||}
\hline Dependent variable & constant & $\left(\frac{1}{T} \sum_{1}^{T}\left(\log \left(R_{m t}\right)-\log \left(\bar{R}_{m}\right)\right)^{2}\right)^{1 / 2}$ \\
\hline$\frac{1}{T} \sum_{t=1}^{T}$ news $_{m t}$ & 14.19 & $\mathbf{2 . 4 5}$ \\
& $(0.19)$ & $(0.39)$ \\
\hline
\end{tabular}

Table 2: News and payoff volatility by country. Cross-section results from regressing a market's average number of news stories on the standard deviation of its asset payoffs. All tables show standard errors in parentheses.

Table 2 shows that the mean number of news stories in a country is positively and significantly correlated with the variance of the country's asset payoffs. Since the estimation treats each country as one observation, there are only 23 data points. Also, the estimation ignores cross-country correlation in price and news shocks. ${ }^{11}$

The next step uses the full panel of data to estimate the relationship between payoff volatility and information with seemingly unrelated regressions for each country. The model predicts that an increase in log volatility, total volatility or payoff levels should cause information to become more valuable. Table 3 shows that all three measures of volatility covary positively with news. The coefficient on log payoff volatility predicts that a $50 \%$ change in payoffs $\left(\Delta \log (R)^{2}=0.25\right)$ generates 15 extra stories, that week, in the Financial Times.

An issue that arises from this estimation is that both variables are highly persistent. Autocorrelation of errors is a concern. Estimating a non-linear least squares equation that includes a lagged estimation error to correct for autocorrelation produces a return volatility coefficient estimate of 38.4 with a standard error of 4.21 .

\footnotetext{
${ }^{10}$ In fact, an increase in any parameter that would be market-specific (not a preference parameter for investors that would apply equally to all markets) and would increase price volatility would also increase information demand.

${ }^{11}$ The average price correlation between country pairs is 0.35 , and the average correlation in news stories in 0.26 . The average correlation between country pairs is 0.28 for log changes in price, and 0.13 for log changes in news.
} 


\begin{tabular}{||c|c|c|c||}
\hline $\begin{array}{c}\text { Dependent } \\
\text { variable }\end{array}$ & $\begin{array}{c}\text { Independent } \\
\text { variable }\end{array}$ & $\begin{array}{c}\text { Regression } \\
\text { coefficient }\end{array}$ & $\begin{array}{c}\text { with dividend } \\
\text { instruments }\end{array}$ \\
\hline news $_{m t}$ & $\begin{array}{c}\text { log payoff } \\
\text { volatility }\end{array}$ & $\begin{array}{c}58.40 \\
(12.08)\end{array}$ & 196.81 \\
& payoff & 1.93 & 8.22 \\
\hline news $_{m t}$ & volatility $\left(* 10^{-4}\right)$ & $(0.23)$ & $(1.24)$ \\
\hline news $_{m t}$ & payoff $\left(* 10^{-3}\right)$ & 3.26 & 6.44 \\
& & $(0.27)$ & $(0.63)$ \\
\hline
\end{tabular}

Table 3: News and payoff volatility over time. Panel estimation results from regressing number of news stories on asset payoff $(\mathrm{R})$ volatility and country fixed-effects. Price indices are divided by their country mean. Seemingly unrelated regression estimation allows for contemporaneous correlation across countries and heteroscedasticity. Instrumental variables are the news volatility variable, dividends, in levels, changes and squared changes, and 8 lags of the volatility variable. (23 countries, 12,194 obs.)

While these covariances provide support for the model, they do not speak to the causal relationship between asset volatility and news. For a causal relationship to be established, instruments that are exogenous with respect to news are needed. Payoff volatility is instrumented with dividends, dividend changes, dividend volatility, and 8 lags of price volatility (table 3, column 2). ${ }^{12}$ Dividends are valid instruments because they are strongly related to payoffs $\left(R^{2}=0.65\right)$, and are not affected by news provision. News affects asset markets by reducing the conditional variance of expectations about current or future conditions. Because dividends are not expectations-driven, but are largely pre-determined outcomes of previous decisions about inputs, they are independent of news.

One might argue that dividends respond to changes in future expected cash flows, and therefore to news about future economic conditions. However, changes in fundamentals that would affect cash flows are exactly what dividend changes are intended to capture. Bad news might make dividends fall. The fact that the bad news is printed in the newspaper does not provide information to managers that would decrease dividends further. Dividends are good instruments not because they are unaffected by news content, but because they are not dependent on news provision.

The reason volatility increases the demand for news is that the increase in risk makes information more valuable. As a robustness check, I redo each estimation, including information volatility as a control variable. (appendix C). The results are quantitatively similar.

One of the goals of this exercise was to show that news is being affected by asset markets. While the correlation results cannot speak to causality, the instrumental variables approach does

\footnotetext{
${ }^{12}$ Results are qualitatively unchanged if lags are removed as instruments.
} 
suggest a causal relationship. To make this point more directly, I test the null hypothesis that news is exogenous in the time series with respect to asset payoff volatility. Table 4 shows that this hypothesis is strongly rejected.

\begin{tabular}{||l|c|c||}
\hline Null Hypothesis & F-stat & P-value \\
\hline News is exogenous with respect to payoff volatility & 4.04 & $5 * 10^{-11}$ \\
\hline
\end{tabular}

Table 4: Granger test of news exogeneity with respect to asset payoff volatility. Test includes 25 lags of each variable.

\section{News and Asset Price Levels}

When countries appear in the news more often, they should have higher asset prices, on average, because the information conveyed in the news stories decreases the investment risk. The next step uses the full panel to estimate the relationship between news and price. Because price indices are not comparable across countries, a country fixed effect is included. The result (in table 5) suggests that a one standard deviation increase in news stories (8.2 stories) coincides with a $\$ 2.30$ increase in the country's asset price index, a $1 \%$ increase over the average price level.

\begin{tabular}{||c|c||}
\hline Dependent variable & news $_{m t}$ \\
\hline$P_{m t}$ & $\mathbf{0 . 2 8}$ \\
& $(0.03)$ \\
\hline$P_{m t} / d_{m t}$ & $\mathbf{0 . 1 8}$ \\
& $(0.02)$ \\
\hline
\end{tabular}

Table 5: News and Price Level. Time-series results from regressing price, or price-dividend ratio, on the number of news stories and country fixed-effects. Seemingly unrelated regression estimation allows for contemporaneous correlation across countries and heteroscedasticity. (12,194 observations)

Again, the issue of autocorrelated errors, or even possibly unit root errors arises. Here, the theory provides a simple solution. When news coverage increases, prices should rise, holding payoffs constant. This implies an increase in the price-dividend ratio $(P / D)$. Using $P / D$ as the dependent variable, instead of price, produces a Durbin-Watson statistic of 1.88. This is a rejection of serially correlated errors. The strong positive relationship between news and $P / D$ reconfirms the theory's prediction.

The question of an external event increasing news and price for reasons outside the model is again an important one. Unfortunately, there is no valid instrument for news. To instrument for 
news, one would want a variable that affected news, but not asset prices. The theory is explicitly about asset payoff relevant news. This news is, by definition, not independent of the asset price.

Two factors mitigate this concern. First, events that create news are not inherently good or bad. Large events in the news are likely to affect asset prices, but are not more likely to increase than to decrease the asset's expected value. The only systematic effect of news on price might be to reduce prices by increasing volatility and risk. This relationship would negatively bias the news coefficient. It could not explain the positive relationship between news and price. Furthermore, appendix $\mathrm{C}$ shows that controlling for price or payoff volatility does not significantly change the coefficient estimates.

\section{Simultaneous Equation Estimation}

Because exogenous events could affect price and news through mechanisms outside the model, the last step estimates price and news as a system of equations. The estimation method, three stage least squares, accommodates error correlation across the two equations and across price and news in every country. This method also allows the inclusion of dividends as instruments for payoff volatility. Table 6 features positive coefficients for news on price and for volatility on news, as predicted by the theory.

\begin{tabular}{||l|c||}
\hline News on Price & news $_{m t}$ \\
\hline Dependent variable & $\mathbf{1 . 3 5}$ \\
$P_{m t}$ & $(0.03)$ \\
\hline Payoff Volatility on News & $\left(\Delta \log \left(R_{m t}\right)\right)^{2}$ \\
\hline Dependent variable: & $\mathbf{1 7 2 . 7 5}$ \\
news $_{m t}$ & $(18.06)$ \\
\hline \hline
\end{tabular}

Table 6: Panel estimation results from simultaneously regressing price on the number of news stories, and news on payoff volatility. Payoff volatility is instrumented with contemporaneous and 1-period lagged dividend levels and dividend volatility, and one lag of payoff volatility. All equations include country fixed effects. Three stage least squares estimation allows for heteroscedasticity and contemporaneous correlation across equations and countries. (12,194 observations for each equation)

Allowing cross-equation error correlation increases the coefficient of news on price almost fivefold. This increase results from the negative correlation of estimation residuals between the price and news equations. Exogenous positive shocks to news make exogenous negative shocks to price more likely. Residual correlations vary by country, ranging from -0.64 to 0.11 , with an average of 
-0.17 . Their origin is the presence of news as an independent variable in the first equation and a dependent variable in the second. The consequence of failing to account for this correlation is that increases in news, because they are often correlated with decreases in prices, are estimated to have a less positive price effect. By neglecting to account for the way in which asset markets generate demand for news, previous work may have underestimated the positive relationship between news and price.

To understand the potential magnitude of the news effect on asset price, consider the following example. Between 1989 and 1992, the average number of Financial Times news stories per week on Thailand was 3.8 , and the average price index was 164 . In 1996-97, the average number of news stories was 19.8, and the average price index was 243. An increase of 16 news stories per week corresponds to a 22-point increase in the price index. If the correlations reported in table 6 are due to forces in the model, then $28 \%$ of the increase in Thai asset prices was due to news and the remaining $72 \%$ to changes in fundamentals.

\section{Evidence of Herding}

According to the theory, news can drive a wedge between prices in similar asset markets. When news provision is low, the information transmission constraint does not bind and markets have no effect on each other. It is only when total information demand is high that conditions for information crowd-out and herds arise. Therefore, price dispersion and news should be positively correlated.

To test this hypothesis, I regress the dispersion of prices each week on the week's average number of news stories per emerging market. The results (in table 7) support the theory's prediction. The results are for the unbalanced panel. Restricting the data to the period in which all countries have price data (February 1997 - June 2002, 282 observations) results in a smaller coefficient on news (2.82) that is still statistically significant at the $99 \%$ level.

While the previous results established that information markets and asset markets are closely connected, this is the result that most clearly distinguishes this theory from other information-based theories of asset price fluctuations. Without complementarity in information markets, information 


\begin{tabular}{||l|c|c||}
\hline Dependent variable & constant & $\frac{1}{M} \sum_{m=1}^{M}$ news $_{m t}$ \\
\hline$\left(\frac{1}{M} \sum_{m=1}^{M}\left(P_{m t}-\bar{P}_{t}\right)^{2}\right)^{1 / 2}$ & 84.35 & $\mathbf{8 . 4 1}$ \\
& $(7.78)$ & $(0.49)$ \\
\hline
\end{tabular}

Table 7: Test of the herding hypothesis: Price dispersion increases with news. Price dispersion is a time series of the standard deviation of prices across the 23 emerging markets. News is the total number of news stories for all emerging markets per week. Price dispersion increases when news is abundant. (704 observations)

would be evenly distributed across all markets and would not increase price dispersion. Only an information-based complementarity would cause asset market dispersion to fluctuate with news.

\section{Conclusion}

Media frenzies are an abundance of information provided to investors about an asset or class of assets by a competitive market for information. The non-rival nature of information and the resulting price complementarity naturally create the conditions for information herds and frenzies to arise. Media frenzies raise asset prices by reducing the uncertainty about the asset's payoff. In a single market, media frenzies increase prices and price volatility in what appears to be an asset-buying frenzy. In multiple markets with trade-offs in information demand, a media frenzy in one market raises the market price and increases the cross-sectional price variance. The resulting price path looks like herds of investors stampeding from one market to the next.

Using price complementarities in information to generate asset market frenzies avoids some of the problems of earlier models. It avoids the criticism levied against the herding models that their discrete choice space is needed (Lee 1993, Vives 1993) and that market clearing prices interfere with the effect (Avery and Zemsky, 1998). This bubble-like outcome does not rely on agents who are not subject to transversality conditions (as in Blanchard and Watson, 1982), or are otherwise not fully rational. Deviations from fundamentals reflect only the reduced investment risk that accompanies close media scrutiny.

Complementarity of information acquisition is not limited to settings where information is purchased in a competitive market. The idea can be extended to more informal settings as well. Consider the following example of an individual learning in the presence of network externalities. Suppose that all information is freely available. However, an investor must decide whether or not to 
exert effort to find news which reveals asset-payoff-relevant information. Other people the investor meets can alert him to events and news of interest, reducing the required search effort to discover the related information. Such a setting could produce an information complementarity where other people knowing information makes acquiring that same information more attractive.

Introducing cross-market information interactions into the theory could generate contagion: high correlation in countries' prices when prices are low and information is scarce. Complementarity magnifies price volatility as markets reinforced each others' booms and crashes. Information substitutability, arising from correlation in market fundamentals, generates price correlation that is strongest in crises. If market x's signal is informative about market y, then beliefs about y react to news about $\mathrm{x}$. The reaction will be strongest when information is scarce. Information is scarce when expected payoffs and price are low. Countries where the market for information is thin may be particularly susceptible to contagion because high variance prior beliefs allow small pieces of new information to move beliefs, and therefore prices, substantially.

Media markets could also provide insight into the home bias puzzle. In a coordination model with potential multiple equilibria, a natural question is whether focal points exist. Local companies may provide a natural focal point for news providers, prone to herding. An abundance of low-cost information available to local residents will increase their demand for the asset.

Modelling media coverage also provides a stronger microeconomic foundation for models that use time-varying information flows to generate asymmetry (Veldkamp, 2002, Van Nieuwerburgh and Veldkamp, 2002). Information, such as news stories, that becomes abundant when the market is strong generates sudden crashes and gradual booms. When fundamentals are strong and asset prices are high, media frenzies arise and agents become well-informed. This model provides a market mechanism that ties information flow to asset prices in the way needed to generate this asymmetry.

Media frenzies rely crucially on the high fixed cost and low marginal cost of information production. As a result, the theory predicts that innovations such as the internet that reduce the marginal cost of information provision will make media-driven frenzies increasingly common. This prediction seems roughly in line with recent history and offers a warning about the future volatility 
of asset markets.

\section{References}

[1] Avery, Christopher and Zemsky, Peter. "Multidimensional Uncertainty and Herd Behavior in Financial Markets." The American Economic Review, September 1998, 88(4), pp.724-748.

[2] Admati, Anat and Pfleiderer, Paul." A Monopolistic Market for Information." Journal of Economic Theory, 1986, v.39, pp.400-438.

[3] Banerjee, Abhijit. "A Simple Model of Herd Behavior." The Quarterly Journal of Economics, August 1992, 107(3), pp. 797-817.

[4] Barlevy, Gadi and Veronesi, Pietro. "Information Acquisition in Financial Markets." Review of Economic Studies January, 2000.

[5] Bikhchandani, S., Hirshleifer, D., and Welch, Ivo. "A Theory of Fads, Fashion, Custom, and Cultural Change as Information Cascades." Journal of Political Economy, 1992, 100, pp. 9921026 .

[6] Blanchard, Olivier and Watson, Mark. "Bubbles, Rational Expectations, and Financial Markets." in Paul Wachtel ed.: Crises in the Economic and Financial Structure. Lexington Books, Lexington, MA, 1982.

[7] Chari, V.V. and Kehoe, Patrick. "Hot Money." Federal Reserve Bank of Minneapolis Staff Report, no. 228, March 2001.

[8] Froot, Kenneth; Scharfstein, David; Stein, Jeremy. "Herd on the Street: Informational Inefficiencies in a Market with Short-Term Speculation." Journal of Finance, 1992, v.47(4), pp.1461-84.

[9] Grossman, Sanford and Stiglitz, Joeseph. "On the Impossibility of Informationally Efficient Markets." American Economic Review, 1980 , vol.70 (3), pp.393-408.

[10] Lee, In-Ho. "On the Convergence of Informational Cascades." Journal of Economic Theory, 1993, v.61, pp.395-411.

[11] Levin, Andrew; Lin, Chien-Fu and Chu, James. "Unit Root Tests in Panel Data: Asymptotic and Finite-Sample Properties." Journal of Econometrics, 2002, v.108, pp.1-24.

[12] Mankiw, Gregory; Romer, David and Shapiro, Matthew. "Stock Market Forecastability and Volatility: A Statistical Appraisal." Review of Economic Studies, 1991, v.58, pp.455-77.

[13] Mitchell, Mark and Mulherin, Harold. "The Impact of Public Information on the Stock Market." The Journal of Finance, 1994, v.49 (3), pp.923-950.

[14] Perloff, J.M. and Salop, S.C. "Equilibrium with Product Differentiation." Review of Economic Studies, v.52, pp.107-120.

[15] Roll, Richard. " $R$ " The Journal of Finance, 1988, vol.43 (2), pp.541-566. 
[16] Romer, Paul. "Endogenous Technological Change." Journal of Political Economy, 98(5), 1990, pp.S71-S102.

[17] Shapiro, Carl and Varian, Hal. Information Rules. Harvard Business School Press, 1998.

[18] Shiller, Robert. Irrational Exuberance. Princeton University Press, Princeton, NJ, 2000.

[19] Sims, Christopher. "Implications of Rational Inattention." mimeo, 2001.

[20] Van Nieuwerburgh, Stijn and Veldkamp, Laura. "Learning Asymmetries in Real Business Cycles." INSEAD Working Paper, 2002.

[21] Veldkamp, Laura. "Slow Boom, Sudden Crash." SIEPR Discussion Paper no.00-16, 2000.

[22] Vives, Xavier. "How Fast Do Rational Agents Learn?" Review of Economic Studies, 1993, v.60, pp.329-47.

[23] Vives, Xavier. Oligopoly Pricing. MIT Press: Cambridge, MA. 1999.

[24] Welch, Ivo. "Sequential Sales, Learning and Cascades." The Journal of Finance, June 1992, 47(2), pp. 695-732.

\section{A Appendix}

\section{A.1 Proof of Proposition 1}

When information demand is positive, equilibrium demand is a $\lambda$ such that the net benefit of information purchase is zero. Let payoff variance be denoted $\sigma_{\theta t} \equiv \rho \theta_{t} \sigma_{\eta}$. Manipulating the net benefit equation 6 and setting the benefit of information (left side of equation 7 ) equal to its cost in utility units (right side of 7 ) yields the equilibrium information demand: ${ }^{13}$

$$
\frac{\sigma_{x}^{2}\left(a \sigma_{\epsilon} / \lambda_{t}\right)^{2}}{1+\left(\sigma_{x}^{2} / \sigma_{\theta t}^{2}\right)\left(a \sigma_{\epsilon}^{2} / \lambda_{t}\right)^{2}}=e^{2 a\left(c\left(\lambda_{t}\right)+\tilde{\psi}\right)}-1
$$

\section{Model I: Equilibrium price equals average cost $(c=\chi / \lambda)$}

Proof: Suppose the equilibrium information price was above average cost. Then, an alternate supplier could enter the market with a slightly lower price, and make a profit. If a supplier set price below marginal cost, they would make a loss. This strategy would be dominated by no information provision. If there are two or more suppliers, then either price is above marginal cost, which can't be an equilibrium by the first argument, or both firms price at (or below) marginal cost, split the market, and make a loss, which is dominated by exit.

\section{Model II: Cournot Model}

Given a quantity of information supplied to the market, the asset price and demand will be identical to the Bertrand case. What changes in a Cournot model is the quantity of information provided. To solve for that quantity, begin by showing that one firm always wants to maintain a monopoly position in the information market, rather than accommodate an entrant. Suppose a firm produced a quantity of information $Q_{1}$, measured in signals per capital, such that a second producer could produce a quantity $Q_{2}$ for a profit $\pi\left(Q_{2}\right) \geq 0$. Then, the incumbent firm could do strictly better by producing an amount $Q_{1}+Q_{2}$, and capturing the additional profit $\pi\left(Q_{2}\right)+\chi>0$. The $\chi$ term enters because the firm does not have to bear the production fixed cost twice.

Now, the problem can be formulated as a constrained maximization where the incumbent maximizes profit, subject to the constraint that he must deter entry. Let $P$ denote the price of information, $Q_{1}$ the incumbent's quantity of signals per capita and $Q_{2}$ the challenger's.

$$
\max _{Q_{1}} P\left(Q_{1}\right) * Q_{1}
$$

\footnotetext{
${ }^{13}$ For a derivation of this expression, see appendix B of Grossman and Stiglitz (1980). This equilibrium condition ignores integer constraints on the number of agents.
} 


$$
\text { s.t. } \max _{Q_{2}} P\left(Q_{1}+Q_{2}\right) * Q_{2} \leq \chi
$$

Rearranging equation 7 yields a price-quantity relationship for information demand:

$$
P(Q)=-\frac{1}{2 a} \ln \left(\frac{Q^{2}+M}{Q^{2}+M+M N}\right)
$$

where $M=\left(\sigma_{x} / \sigma_{\theta}\right)^{2}\left(a \sigma_{\epsilon}^{2}\right)^{2}$ and $N=\left(\sigma_{\theta} / \sigma_{\epsilon}\right)^{2}$.

The negative relationship between price and quantity comes from the demand equation (8). The negative first derivative of the demand equation is sufficient to prove the proposition.

\section{Model III: Monopolistic Competition}

Following Perloff and Salop (1985), free-entry in the information market implies that equilibrium information price $c\left(\lambda_{t}\right)$, times the number of agents who buy information $N \lambda_{t}$, times the probability an agent most prefers information of type $j, H_{j}$, must be equal to the fixed cost of entry.

$$
c\left(\lambda_{t}\right) \lambda_{t} H_{j}=\chi
$$

As in Perloff and Salop, I ignore the integer constraints on the number of news types. In equilibrium, each type $j$ attracts an equal share of the market. Let $n_{J}$ be the number of types supplied in equilibrium.

$$
c\left(\lambda_{t}\right) \lambda_{t}=\chi n_{J}
$$

The first-order condition of the news supplier's profit maximization problem yields $p=\frac{b}{n_{J}}$. Combining this with the free-entry conditions, we get equilibrium price and number of firms.

$$
\begin{gathered}
n_{J}=\left[\frac{b \lambda_{t}}{\chi}\right]^{1 / 2} \\
p=\left[\frac{b \chi}{\lambda_{t}}\right]^{1 / 2}
\end{gathered}
$$

The equilibrium price is decreasing in $\lambda_{t}$. Thus, the more people buy news, the lower the price of news will be.

\section{A.2 Proof of Proposition 2: Information Complementarity}

$B\left(\lambda ; \theta_{t}\right)$ is the net benefit of buying a signal. Grossman and Stiglitz (1980, appendix B) show that equation 1 can be expressed as

$$
B\left(\lambda ; \theta_{t}\right)=\left[1+\frac{\sigma_{x}^{2} *\left(a \sigma_{\epsilon} / \lambda_{t}\right)^{2}}{1+\sigma_{x}^{2} / \sigma_{\theta t}^{2} *\left(a \sigma_{\epsilon}^{2} / \lambda_{t}\right)^{2}}\right]^{1 / 2}-e^{2 a\left(c\left(\lambda_{t}\right)+\tilde{\psi}\right)}
$$

To begin, assume that $\tilde{\psi}=0$ (as in Bertrand or Cournot markets). Differentiation with respect to $\lambda$ yields

$$
\frac{\partial B\left(\lambda ; \theta_{t}\right)}{\partial \lambda}=-\lambda a^{2} \sigma_{x}^{2} \sigma_{\epsilon}^{2} \frac{\left[\lambda^{2}+a^{2} \sigma_{x}^{2} \sigma_{\epsilon}^{2}\left(1+\sigma_{\epsilon}^{2} / \sigma_{\theta}^{2}\right)\right]^{-1 / 2}}{\left[\lambda^{2}+\sigma_{x}^{2} / \sigma_{\theta}^{2}\left(a \sigma_{\epsilon}^{2}\right)^{2}\right]^{3 / 2}}-a c^{\prime}(\lambda) e^{a c(\lambda)}
$$

The first term is zero when $\lambda=0$ and is negative for all $\lambda>0$. This is because the benefit of information declines as the price level becomes more informative. According to proposition $1, c^{\prime}(\lambda)<0$. Thus, the second term is strictly positive for all $\lambda \geq 0$. Since $\frac{\partial B\left(\lambda ; \theta_{t}\right)}{\partial \lambda}$ is continuous in $\lambda>0$, and is strictly positive in the neighborhood of zero, the proposition follows.

When $\tilde{\psi} \neq 0$, there is a second positive externality of an increase in demand for news: increased diversity of available news types. Note that $n_{J}$ in proposition 1 proof, is increasing in $\lambda$. The expected lowest individual-specific cost of information for a given agent $i$ is

$$
E[\bar{\psi}]=\frac{b}{n_{J}+1} .
$$

As the number of news types $n_{J}$ increases, $E[\bar{\psi}]$ decreases. Every agent must be made weakly better off with more available news types to choose from. Therefore, the second term in the derivative of the net benefit equation with news types is

$$
-a\left(c^{\prime}(\lambda)+\partial \tilde{\psi} / \partial \lambda\right) e^{2 a\left(c\left(\lambda_{t}\right)+\tilde{\psi}\right)}
$$

which is still strictly increasing near zero. 


\section{A.3 Proof of Proposition 3: Information Equilibrium Transition Rule}

Step 1: If $B(\lambda)>0$ holds for any $\lambda>0$, then there exists an equilibrium $\lambda^{e}>0$.

A level of information demand, $\lambda^{e s}$ is an equilibrium if the people who buy information weakly prefer to do so $\left(B\left(\lambda^{e}\right) \geq 0\right)$ and, either $\lambda^{e}=1$, or an uninformed person weakly prefers staying uninformed $\left(B\left(\lambda^{e}+\epsilon\right) \leq 0, \epsilon>0\right)$.

Suppose that there is some $\lambda$ such that $B(\lambda)>0$ but no equilibrium exists. If $\lambda$ is not an equilibrium, then it must be that $B(\lambda+\epsilon)>0$. By induction, if $B(\lambda+\tilde{\epsilon})$ is not an equilibrium, for any $\tilde{\epsilon}>0$ then it must be that $B(1)>0$. But, then $\lambda=1$ is an equilibrium, which is a contradiction. Step 2: A positive information equilibrium

exists iff

$$
\left\{\sigma_{\theta t+1}^{2}+\sigma_{\epsilon}^{2}+\sigma_{\theta t+1}^{2}\left[1+\left(\frac{a \sigma_{\epsilon} \sigma_{x}}{\lambda_{t} \sigma_{\theta t+1}}\right)^{2}\right]^{-1}\right\}^{1 / 2} \geq \exp \left[a\left(c\left(\lambda_{t}\right)+\tilde{\psi}\right)\right] \sigma_{\epsilon} \quad \text { for some } \lambda_{t} \epsilon(0,1) .
$$

Using step 1 and the Grossman Stiglitz result (p.405) that $\operatorname{Var}\left[u \mid P_{\lambda}\right]=\sigma_{\theta}^{2}+\sigma_{\epsilon}^{2}-\frac{\sigma_{\theta}^{2}}{1+\left(a \sigma_{\epsilon}^{2} /\left(\lambda \sigma_{\theta}\right)\right)^{2} \sigma_{x}^{2}}$. Inequality (10) follows. Step 3: There exists a $\theta^{\star}$ such that for all $\theta \geq \theta^{\star},(10)$ holds.

Only two terms in (10) vary: $\lambda$ and $\sigma_{\theta}$. Let $\theta^{\star}$ be the lowest $\theta>0$ such that (10) holds for some $\lambda$. Let the $\lambda$ that satisfies (10) at $\theta^{\star}$ be $\lambda^{e}$.

Partial differentiation shows that the left side of (10) is increasing in $\sigma_{\theta}$. Furthermore, $\sigma_{\theta}$ is increasing in $\theta$, when $\theta>0$. Thus, for any $\theta \geq \theta^{\star}$, (10) holds at $\lambda=\lambda^{e}>0$. Step 4: For $\theta_{t}>\theta^{\star}$, an equilibrium where $\lambda_{t}=0$ does not exist.

Suppose $\lambda_{t}=0$ was an equilibrium. Then, some agent could decide to discover information at a per-capita cost $\chi$ and sell it at a price $\chi / \lambda^{e}+\epsilon$. Since $\theta_{t}>\theta^{\star}$, the net benefit curve lies strictly above zero at $\lambda^{e}-\epsilon$ and the information producer can capture positive surplus by raising price. Therefore, zero information production cannot be an equilibrium strategy for all agents. Step 5: When $\theta_{t} \leq \theta^{\star}$, the equilibrium is $\lambda_{t}=0$.

If (10) does not hold for any $\lambda>0$, then there cannot be an equilibrium where $\lambda^{e}>0$. If there were, then all agents who purchase information would be strictly better off not purchasing it.

A no-information equilibrium exists because neither purchasers nor suppliers want to deviate from their equilibrium strategies. No purchaser would purchase information. (10) rules this out. No supplier would want to supply information because at any price greater than average cost, the demand for the information would be zero.

\section{A.4 Proof of Proposition 4: Payoff Volatility Increases Information}

Recall that $\sigma_{\theta t}$ is linear in $\theta_{t}$, so that $\forall \theta_{t}>0, \sigma_{\theta t}$ in increasing in $\theta_{t}$. From proposition 4, we know that for $\theta_{t}<\theta^{\star}$, $\lambda_{t}=0$. For $\theta_{t} \geq \theta^{\star}, \lambda_{t}>0$. In a positive information equilibrium, information demand is determined implicitly by equation 7. Applying the implicit function theorem to $B(\lambda)=0$ (equation 9) in a region where $B^{\prime}(\lambda) \geq 0$, which is a necessary condition for a stable positive-information equilibrium, yields $\partial \lambda_{t} / \partial \sigma_{\theta t}>0$.

\section{A.5 Proof of Proposition 5: Information Increases Asset Price}

Begin by taking the expectations of asset demand, conditional on $\theta_{t}$. For agents who purchase information, expected demand is

$$
\frac{E\left[\theta_{t+1} \mid \theta_{t}\right]-r E\left[P \mid \theta_{t}\right]}{a \sigma_{\epsilon}}
$$

For agents who do not purchase information in the positive information equilibrium,

$$
\begin{gathered}
\frac{E\left[E\left[\theta_{t+1} \mid P_{t}, \theta_{t}\right] \mid \theta_{t}\right]-r E\left[P \mid \theta_{t}\right]}{a \operatorname{Var}\left[u_{t+1} \mid P_{t}\right]} \\
=\frac{E\left[\theta_{t+1} \mid \theta_{t}\right]-r E\left[P \mid \theta_{t}\right]}{a \operatorname{Var}\left[u_{t+1} \mid P_{t}\right]}
\end{gathered}
$$

by iterated expectations. Thus, expected total demand in the information equilibrium is

$$
\lambda \frac{E\left[\theta_{t+1} \mid \theta_{t}\right]-r E\left[P \mid \theta_{t}\right]}{a \sigma_{\epsilon}^{2}}+(1-\lambda) \frac{E\left[\theta_{t+1} \mid \theta_{t}\right]-r E\left[P \mid \theta_{t}\right]}{a \operatorname{Var}\left[u_{t+1} \mid P_{t}\right]}
$$


Note that the variance term $\operatorname{Var}\left[u_{t+1} \mid P_{t}\right]$ is not stochastic, conditional on $\theta_{t}$ because it only depends on parameters that can be deduced from $\theta_{t}$. In the no-information equilibrium, let $P^{U}$ denote the 'uninformed' asset price. Then, expected demand is:

$$
\frac{E\left[\theta_{t+1} \mid \theta_{t}\right]-r E\left[P^{U} \mid \theta_{t}\right]}{a \sigma_{\epsilon}^{2}+\sigma_{\theta}^{2}} .
$$

Since demand must be equal to $x_{t}$ in both equilibria, the two expressions for demand must equal each other.

$$
\lambda \frac{E\left[\theta_{t+1} \mid \theta_{t}\right]-r E\left[P \mid \theta_{t}\right]}{a \sigma_{\epsilon}^{2}}+(1-\lambda) \frac{E\left[\theta_{t+1} \mid \theta_{t}\right]-r E\left[P \mid \theta_{t}\right]}{a \operatorname{Var}\left[u_{t+1} \mid P_{t}\right]}=\frac{E\left[\theta_{t+1} \mid \theta_{t}\right]-r E\left[P^{U} \mid \theta_{t}\right]}{a \sigma_{\epsilon}^{2}+\sigma_{\theta}^{2}}
$$

The fact that information decreases the variance of the asset payoff implies that $\sigma_{\epsilon}^{2}+\sigma_{\theta}^{2}>\operatorname{Var}\left[u_{t+1} \mid P_{t}\right]>\sigma_{\epsilon}^{2}$. This implies that $E\left[P \mid \theta_{t}\right]>E\left[P^{U} \mid \theta_{t}\right]$.

The fact that $\operatorname{corr}\left(P_{t}, u_{t+1} \mid \theta_{t}\right)$ is increasing in $\lambda$ means that $\operatorname{Var}\left[u_{t+1} \mid P_{t}\right]$ is decreasing in $\lambda$. Following the same steps as above, one can show that if $\lambda_{1}>\lambda_{2}$, then $E\left[P_{1} \mid \theta_{t}\right]>E\left[P_{2} \mid \theta_{t}\right]$.

\section{A.6 Proof of Proposition 6: Herding}

Suppose that $\tilde{m}$ markets have identical histories $\left(\theta^{t+1}, \epsilon^{t}, x^{t}\right)$ and identical parameters and that agents can purchase at most $k$ signals. Let $\lambda^{\star}=\operatorname{argmax}_{\lambda} B(\lambda)$. If $\lambda^{\star}>k / \tilde{m}$, then the price of the risky asset will not be identical across markets. It will be higher in the market with higher information demand $\lambda_{m t}$.

Suppose not. Suppose that the price of the risky asset is identical in all $\tilde{m}$ markets. From proposition 5 we know that information increases the asset price. So for each market to have the same asset price, given the same histories, they must have the same amount of information as well. Suppose $\lambda=0$ in all markets. For this to be an equilibrium, is must be that $\operatorname{argmax}_{\lambda} B(\lambda)=0$. But then $\lambda^{\star}=0<k / \tilde{m}$, which contradicts one of the conditions of the proposition. Therefore, all markets have the same positive amount of information $\lambda_{m}$. The information capacity constraint says that the maximum fraction of informed agents in each market would be $\lambda_{m}=k / \tilde{m}<\lambda^{\star}$.

Since each market has a $\lambda_{m}<\lambda^{\star}$, the net benefit of information in each market is increasing in $\lambda_{m}$. This means an agent in one market, who gets a net benefit of $B\left(\lambda_{m}\right)$ from his information, has an incentive to purchase a signal in another market to get a net benefit of $B\left(\lambda_{m}+\epsilon\right)>B\left(\lambda_{m}\right)$. Therefore, this cannot be an equilibrium.

The fact that the price will be higher in the market with the higher $\lambda_{m}$ follows directly from proposition 5 .

\section{B An Extended Model with News Stories}

This section describes a model of news supply where news stories are varieties of different information. The equilibrium number of stories $n_{J}$ increases with the fraction of informed agents $\lambda$ in the original model.

Investors, preferences, asset markets, and asset payoffs are as described in section 1. Only information markets differ. For a cost $\tilde{\chi}\left(n_{J}\right)$, each information supplier $j$ discovers a different story:

$$
q_{j t}=\theta_{t+1}+\gamma_{j t} \quad \gamma_{j t} \sim N\left(0, \sigma_{\gamma}^{2}\right)
$$

and sells stories - identical copies of $q_{j t}$ - at an endogenous price. $\tilde{\chi}^{\prime}\left(n_{J}\right)>0$. Any agent can become an supplier at any time. Suppliers are price-setting monopolistic competitors. Agents can buy multiple stories.

Consider an agent who has information $\mathcal{F}_{i t}$, either purchased or inferred from the price level that leads her to believe the following: $E\left[u_{t+1} \mid \mathcal{F}_{i t}\right]=\hat{\theta}$ and $\operatorname{Var}\left[u_{t+1} \mid \mathcal{F}_{i t}\right]=\tilde{\sigma}_{J}$. Suppose the agent buys an additional story $j$. When no other agents buy $j\left(\lambda_{j}=0\right)$, the price level is uninformative about $q_{j}$. Define $\tilde{\sigma}_{\theta j}$ to be the reduction in payoff variance after observing $q$ when $\lambda_{q}=0$. Define $\tilde{\sigma}_{\epsilon j}$ to be the payoff variance conditional on $\mathcal{F}_{i t}$ and $q_{j}$. $\tilde{\sigma}_{\epsilon j}^{2}=\operatorname{Var}\left[u_{t+1} \mid \mathcal{F}_{i t}, n\right]=\tilde{\sigma}_{J}^{2}-\tilde{\sigma}_{\theta j}^{2}$. Holding these conditional variances fixed, the decision of whether to buy story $j$ takes the same form as that in the original model. The net benefit of buying $j$ when $N \lambda_{j}$ investors also buy $j$ is

$$
\tilde{B}\left(\lambda_{j}, n_{J}\right)=\frac{\sigma_{x}^{2}\left(a \tilde{\sigma}_{\epsilon j} / \lambda_{j t}\right)^{2}}{1+\left(\sigma_{x}^{2} / \tilde{\sigma}_{\theta j}^{2}\right)\left(a \tilde{\sigma}_{\epsilon j}^{2} / \lambda_{j t}\right)^{2}}-e^{\left.2 a \tilde{\chi}\left(n_{J}\right) / \lambda_{j t}\right)}+1 .
$$

What changes when multiple noisy signals - stories - are introduced is that $\tilde{\sigma}_{\theta j}$ changes for each story. Whenever a new story is supplied to the market, it is partially revealed through the equilibrium price level. Both agents who purchase the story, and those who don't, have a lower variance estimate of the payoff.

The net benefit of purchasing the next story increases, due to price complementarity, and then decreases as the price becomes more informative. The parallel between the net benefit for the number of stories and $\lambda$ in the original model cause their equilibrium quantities to move together. 
The force that causes the net benefit of the next story to decrease is more substitutable information. As the number of stories grows, each new story reduces payoff variance less: $\tilde{\sigma}_{\theta j}$ falls. The reason is that in the Bayesian updating formula, a new signal (the story) with the same variance is given less weight when the variance of the prior is less. For example, if the variance of a normally distributed prior is $\tilde{\sigma}_{J}$ and the variance of the signal is $\sigma_{\gamma}$, then the variance of the posterior is $\tilde{\sigma}_{J} \sigma_{\gamma} /\left(\tilde{\sigma}_{J}+\sigma_{\gamma}\right)$. The variance reduction from observing the story is $\tilde{\sigma}_{\theta j}=\tilde{\sigma}_{J}\left(1-\sigma_{\gamma} /\left(\tilde{\sigma}_{J}+\sigma_{\gamma}\right)\right)$, which is increasing in $\sigma_{J}$. So, the larger the prior variance $\sigma_{J}$, the larger the variance reduction $\tilde{\sigma}_{\theta j}$. Because each new story reduces the variance of beliefs that will be the prior beliefs on observing the next story, each new story reduces $\tilde{\sigma}_{\theta j}$.

The force that causes the net benefit of stories to rise is price complementarity. Complementarity in stories arises because each story lowers the fixed cost of discovering all stories. Since the average cost of a story falls, the equilibrium price of stories falls too. This follows from the proof of a declining price in a monopolistic competition model (appendix A.1). Given that $n_{J}$ stories will be produced, consumers view these stories as ex-ante identical. In equilibrium, demand for each story produced $\lambda_{j}$ must be the same for all stories. Appendix A.1 shows that the number of varieties offered my competitive monopolists increases in the demand for each variety. This tells us that $n_{J}$ increases in $\lambda_{j}$. To the extent that $\lambda_{j}$ in this setting is the equivalent of $\lambda$ in the model with one news story, then the number of stories is increasing with $\lambda$.

\section{Data Appendix}

\section{C.1 News and Asset Data: Descriptive Statistics}

News counts are the number of stories in the Financial Times, in a given week, with the country name in the title or lead paragraph of the article. For every country, this series begins in 1/1989 and continues until 6/2002 (703 observations per country). Asset price index is the S\&P /IFCI investible index from their Emerging Markets Database. Price and payoff (total return) data are an unbalanced panel. Many of the markets were not opened to foreign investment until after 1989. The date at which price and payoff indices become available for a country are listed as the start date in table 8. Price and payoff indices are normalized to 100 at the country start date.

\begin{tabular}{||l|c|c|c|c|c|c|c||}
\hline Country & \multicolumn{2}{|c|}{ Number of News Stories } & \multicolumn{3}{c|}{ Asset Price Index } \\
\hline Argentina & mean & min & max & stdev & Start Date & mean & stdev \\
\hline Brazil & 12.5 & 0 & 71 & 8.5 & January 1989 & 695.8 & 321.4 \\
\hline Chile & 19.1 & 0 & 118 & 10.8 & January 1989 & 278.5 & 143.9 \\
\hline China & 6.7 & 0 & 32 & 4.4 & January 1989 & 500.0 & 203.8 \\
\hline Czech Republic & 41.4 & 5 & 114 & 18.0 & September 1993 & 61.3 & 25.7 \\
\hline Egypt & 6.7 & 0 & 47 & 5.3 & April 1996 & 55.0 & 10.1 \\
\hline Greece & 11.8 & 0 & 47 & 4.8 & February 1997 & 62.9 & 25.3 \\
\hline Hungary & 9.7 & 0 & 38 & 5.9 & January 1989 & 378.4 & 216.8 \\
\hline India & 22.7 & 0 & 85 & 10.1 & November 1992 & 90.7 & 20.9 \\
\hline Indonesia & 12.5 & 0 & 87 & 10.4 & September 1990 & 67.8 & 39.2 \\
\hline Israel & 17.4 & 4 & 78 & 8.6 & August 1997 & 138.9 & 26.1 \\
\hline Malaysia & 12.0 & 0 & 50 & 7.5 & January 1989 & 174.7 & 82.3 \\
\hline Mexico & 19.0 & 0 & 71 & 10.8 & January 1989 & 587.6 & 219.4 \\
\hline Morocco & 2.0 & 0 & 16 & 2.0 & February 1997 & 135.4 & 24.5 \\
\hline Peru & 3.9 & 0 & 30 & 3.1 & September 1993 & 169.8 & 39.2 \\
\hline Philippines & 8.6 & 0 & 44 & 5.8 & January 1989 & 159.7 & 84.1 \\
\hline Poland & 13.7 & 1 & 54 & 6.6 & January 1994 & 601.3 & 145.2 \\
\hline Russia & 46.0 & 12 & 193 & 17.7 & February 1997 & 87.4 & 41.9 \\
\hline South Africa & 25.4 & 2 & 71 & 11.0 & January 1994 & 188.2 & 39.5 \\
\hline South Korea & 18.4 & 0 & 82 & 11.6 & January 1992 & 87.7 & 31.9 \\
\hline Taiwan & 10.7 & 0 & 33 & 6.4 & January 1991 & 126.0 & 31.6 \\
\hline Thailand & 10.9 & 0 & 54 & 8.3 & January 1989 & 184.3 & 123.7 \\
\hline Turkey & 11.0 & 0 & 48 & 6.1 & August 1989 & 208.5 & 116.3 \\
\hline All countries & 15.2 & 0 & 193 & 8.2 & & 255.0 & 237.2 \\
\hline
\end{tabular}

Table 8: Descriptive statistics for data set. 


\section{C.2 Robustness Checks}

\section{Payoff Volatility and News}

One of the forces in the model that could create a correlation between payoff volatility and news is news volatility. The reason that the model generates excess volatility is not because the news level is high, but because occasionally the news equilibrium changes, and news volatility is high. To the extent that news level and news volatility are correlated, news volatility could explain the previous regression coefficients, without news being a result of payoff volatility. This section re-runs these regressions, controlling for news volatility to verify that a relationship between payoff volatility and the news level still exists. (Table 9)

\begin{tabular}{||l|c|c|c||}
\hline Dependent variable: & constant & $\operatorname{std}_{m}\left(\log \left(R_{m t}\right)\right)$ & $\operatorname{std}_{m}\left(\log \left(\right.\right.$ news $\left.\left._{m t}\right)\right)$ \\
\hline$\frac{1}{T} \sum_{t=1}^{T}$ news $_{m t}$ & 46.63 & $\mathbf{1 5 . 4 5}$ & -62.59 \\
& $(0.30)$ & $(0.31)$ & $(0.52)$ \\
\hline
\end{tabular}

Table 9: Cross-section results from regressing a market's average number of news stories on its asset payoff volatility. Controlling for news variance isolates the relationship between price volatility and news. Standard errors in parentheses.

The reason payoff volatility increases the demand for news is that the increase in risk makes information more valuable. This holds even after controlling for news volatility. This robustness check works for the panel estimation with and without instruments as well. (Table 10)

\begin{tabular}{||l|c|c||}
\hline Dependent variable: news $_{m t}$ & $\left(\log \left(R_{m t}\right)-\log \left(R_{m(t-1)}\right)\right)^{2}$ & $\left(\log \left(\text { news }_{m t}\right)-\log \left(\text { news }_{m(t-1)}\right)\right)^{2}$ \\
News and payoff & $\mathbf{5 8 . 6 4}$ & -0.06 \\
volatility over time & $(4.89)$ & $(0.07)$ \\
\hline Effect of payoff vol. & $\mathbf{1 5 7 . 9 2}$ & -0.03 \\
on news with IV & $(15.72)$ & $(0.07)$ \\
\hline
\end{tabular}

Table 10: Panel estimation results from regressing number of news stories on asset price (P) or payoff (R) volatility and country fixed-effects. Price indices are divided by their country mean. Seemingly unrelated regression estimation allows for contemporaneous correlation across countries and heteroscedasticity. Controlling for news variance isolates the effect of volatility on news. Instrumental variables are the news volatility variable, dividends, in levels, changes and squared changes, and 8 lags of the volatility variable.

\section{News Increases Price}

Proposition 5 shows that news increases price by reducing the conditional risk of investment. However, the model also predicts that the price level can effect news if it is correlated with price volatility, and therefore payoff volatility in the data. This is the only other relationship between the price level and news identified by the model. To check if the correlation between price and news is robust to price and payoff volatility, I re-estimate including price volatility as a control variable. This inclusion has a negligible effect on the parameter estimates. (Tables 11 and 12)

\begin{tabular}{||l|c|c|c||}
\hline Dependent variable: & constant & $\frac{1}{M} \sum_{m=1}^{M}$ news $_{m t}$ & $\frac{1}{M} \sum_{m=1}^{M}\left(\log \left(R_{m t}\right)-\log \left(R_{m(t-1)}\right)\right)^{2}$ \\
\hline$\frac{1}{M} \sum_{m=1}^{M} P_{m t}$ & 213.56 & $\mathbf{4 . 1 5}$ & -580.69 \\
& $(7.65)$ & $(0.37)$ & $(73.99)$ \\
\hline
\end{tabular}

Table 11: Cross-section average news and price over time, controlling for payoff volatility. Prices increase when news is abundant. Price is the average price index for all countries in the sample, each week. News is the average number of news stories for all emerging markets per week. OLS estimation. White standard errors in parentheses. (704 observations)

\section{Simultaneous Equation Estimation}

The final exercise re-estimate the simultaneous equations system controlling for news variance in the news equation and payoff variance in the price equation. Results in table 13 are very close to those reported in section 6 . 


\begin{tabular}{|c|c|c|}
\hline Dependent variable: & news $_{m t}$ & $\left(\left(P_{m t}-P_{m(t-1)}\right) / \bar{P}_{m}\right)^{2}$ \\
\hline$P_{m t}$ & $\begin{array}{c}\mathbf{0 . 2 4} \\
(0.04)\end{array}$ & $\begin{array}{l}526.8 \\
(52.5) \\
\end{array}$ \\
\hline Dependent variable: & news $_{m t}$ & $\left(\log \left(R_{m t}\right)-\log \left(R_{m(t-1)}\right)\right)^{2}$ \\
\hline$P_{m t}$ & $\begin{array}{c}\mathbf{0 . 3 0} \\
(0.04)\end{array}$ & $\begin{array}{c}-190.9 \\
(33.8)\end{array}$ \\
\hline
\end{tabular}

Table 12: Panel results from regressing price, on the number of news stories, price or payoff volatility, and country fixed-effects. Controlling for volatility isolates the effect of news on the price level. Seemingly unrelated regression estimation allows for contemporaneous correlation across countries and heteroscedasticity. (12,194 observations)

\begin{tabular}{||l|c|c||}
\hline Dependent variable: $P_{m t}$ & news $_{m t}$ & $\left(\log \left(R_{m t}\right)-\log \left(R_{m(t-1)}\right)\right)^{2}$ \\
\hline Effect of News on Price & $\mathbf{2 . 0 4}$ & -350.6 \\
& $(0.02)$ & $(28.4)$ \\
\hline Dependent variable: news $_{m t}$ & $\left(\log \left(R_{m t}\right)-\log \left(R_{m(t-1)}\right)\right)^{2}$ & $\left(\log \left(\text { news }_{m t}\right)-\log \left(\text { news }_{m(t-1)}\right)\right)^{2}$ \\
\hline Effect of payoff & $\mathbf{5 8 . 1 0}$ & 3.23 \\
volatility on news & $(4.37)$ & $(0.22)$ \\
\hline
\end{tabular}

Table 13: Panel estimation results from simultaneously regressing price on the number of news stories, controlling for payoff volatility, and news on payoff volatility, controlling for news volatility. All equations include country fixed effects. Seemingly unrelated regression estimation allows for heteroscedasticity and contemporaneous correlation across equations and countries. (12,194 observations for each equation)

\section{C.3 Unit Root Tests}

Stationarity of the data is a cause for concern. Price data is usually trending and news stories may well be proliferating. This section shows that these concerns are not warranted in this data set.

The news data is the number of stories published per week in one news source: the Financial Times. Figure 5 plots the average number of news stories per emerging market. The number of stories in 2002 is approximately the same and in 1994, but is higher than in the early 90's. An augmented Dickey-Fuller test of each country's news series rejects the null hypothesis of a unit root, at the $1 \%$ significance level, for every country but one - Korea. A unit root for Korean news can be rejected at the $5 \%$ level.

The price data is an emerging market equity price index. The units for all countries indices are U.S. dollars. The solid line in figure 5, representing the average price index level in all emerging markets, has no obvious trend. Augmented Dickey-Fuller tests of individual countries' price series reject the null hypothesis of a unit root at the $5 \%$ level for one country, and at the $10 \%$ level for 5 countries. However, a more powerful test would use all countries' data in a joint stationarity test.

One way to jointly test countries' price data for stationarity is to estimate

$$
\Delta P_{m t}=\sum_{i=1}^{q} \phi_{i} \Delta P_{m(t-i)}+\alpha+\rho P_{m(t-1)}+\epsilon_{m t}
$$

and test the null hypothesis $H_{0}: \rho=0 \alpha=0$. OLS estimation with a t-test rejects the null hypothesis at the $1 \%$ level. It rejects the simple null $\rho=0$ at the $1 \%$ level as well. Estimating by SUR to allow for correlated country shocks and heteroscedasticity, yields the same results. The same system is estimated, allowing $\phi$ and $\alpha$ to be country-specific, as in Levin, Lin and Chu (2002). A likelihood ratio test rejects both $H_{0}: \rho=0 \alpha=0$ and $\tilde{H}_{0}: \rho=0$ at the $1 \%$ level. 


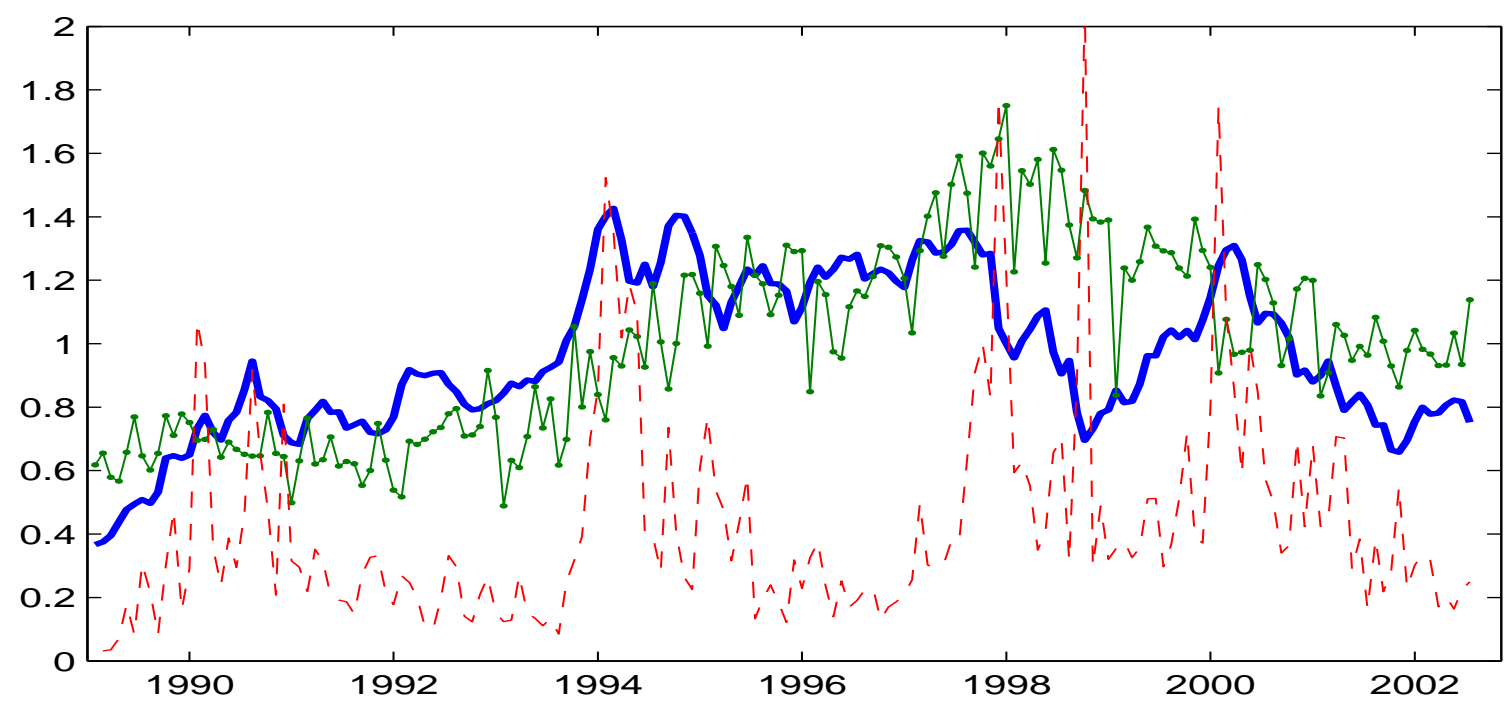

Figure 5: Average price index (solid line), number of news stories (dots), and payoff volatility (dashed line).Monthly data reported. All series are normalized by their respective country means before they are averaged across all emerging markets. 